Review

\title{
Detection of Circulating Tumor DNA in Solid Tumors
}

\author{
Ugo Testa * , Germana Castelli, Elvira Pelosi \\ Department of Oncology, Istituto Superiore di Sanità, Viale Regina Elena 299, 00161 ROME, ITALY; \\ E-Mail: ugo.testa@iss.it
}

* Correspondence: Ugo Testa; E-Mail: ugo.testa@iss.it

Academic Editor: Tapan K Bera

Special Issue: Molecular Cancer Therapeutics

\section{OBM Genetics}

2020, volume 4, issue 3

doi:10.21926/obm.genet.2003114
Received: May 27, 2020

Accepted: July 10, 2020

Published: August 06, 2020

\begin{abstract}
Cancer is characterized by sequential and progressive genetic and epigenetic alterations in key proto-oncogenes and tumor suppressor genes, which ultimately lead to tumor development. Advances in the technology of analysis of molecular mechanisms have increased the efficiency of clinical management of cancer patients. Recent years have witnessed a progressive development in technologies that enable the detection of specific molecular abnormalities associated with various types of solid tumors in body fluids, a process that is globally known as "liquid biopsy". Liquid biopsy is largely based on the circulating free DNA (cfDNA) present in the plasma of healthy individuals and derived either from cell apoptosis or from the active secretion of microvesicles mediated by white blood cells (WBCs). The plasma of cancer patients contains DNA, which is referred to as circulating tumor DNA (ctDNA) and is released by the tumor cells in the form of DNA fragments of various sizes bearing the various types of genetic abnormalities specific to the tumors from which were derived. Sequencing studies conducted with several thousands of cancer patients have revealed that ctDNA accounts for only a fraction of the total DNA, and the size of this fraction varies in relation to tumor burden, tumor site, tumor subtypes, and several other biological properties of the tumor cells. Therefore, the levels of ctDNA are extremely low in several earlystage tumors, requiring highly sensitive methods for the detection of genetic alterations
\end{abstract}

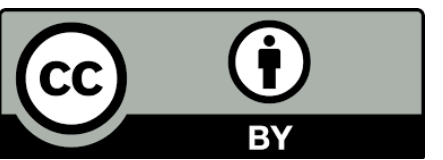

(C) 2020 by the author. This is an open access article distributed under the conditions of the Creative Commons by Attribution License, which permits unrestricted use, distribution, and reproduction in any medium or format, provided the original work is correctly cited. 
occurring at an extremely low allelic ratio. Several studies on advanced solid tumors corroborate the view that in comparison to the standard tissue-based DNA analysis, ctDNA analysis may represent a better approach, which is more convenient, readily accessible, and less invasive. Therefore, ctDNA analysis may contribute to improving the stratification of the patients, supplementing the monitoring of the therapeutic response to treatment, and in certain cases, guiding the therapeutic interventions. Another challenging objective of ctDNA analysis is the monitoring of minimal residual disease (MRD). With rapid achievements in the study of ctDNA, an increasing number of trials that are currently under progress have incorporated liquid biopsy in their design. The majority of these studies are observational or cross-sectional in design, and in several instances, involve the comparison of ctDNA analysis to the conventional investigation approaches as the primary objective.

\section{Keywords}

Cancer, solid tumors, minimal residual disease (MRD), liquid biopsy, precision medicine

\section{Introduction}

The only blood test commonly used for early cancer detection is the measurement of prostatespecific antigen. The other cancer detection tests approved for common use in the medical routine, such as mammography, cervical cytology, and colonoscopy, are not based on the detection of tumor-related molecules in the blood. Therefore, the development of blood-based tests capable of detecting tumors is a necessity, particularly for offering a non-invasive strategy for detecting the presence of tumor cells surviving after the initial treatments.

The increasing understanding of the genetic basis of tumors in the last two decades has led to the development of precision oncology, the main objective of which is to improve the diagnosis and treatment of cancer. The main rationale of this approach is to analyze the genomic and other molecular properties of different cancers, in order to identify the main genetic alterations present in the tumor cells which is responsible for cancer initiation and progression, to determine the altered signaling and biochemical pathways, to classify the various tumors into molecular subtypes, to determine the markers predictive of disease evolution or of response to the treatment to guide the therapeutic choices and to identify the molecular determinants of metastatic behavior [1-3]. Comprehensive multiparametric analyses have led to novel classifications of tumors and an understanding of the molecular aberrations and their roles in various tumor types, along with the identification of novel drug targets, which represent an essential fundamental tool for the development of precision oncology [1-3]. However, molecular profiling requires access to tumor material through invasive procedures, which are not feasible in all cases. Therefore, there is an absolute necessity of developing complementary alternative strategies that would enable an analysis of the tumor cells or the analysis of the molecules released by these cells in the body fluids such as blood. The search for the development of a blood-based non-invasive test for detecting the presence of tumor cells must aim to fulfill the following three essential requisites established by The Evaluation of Genomic Applications in Practice and Prevention: analytical validity, a parameter associated with the evaluation of accuracy, reliability, and reproducibility of a test; clinical validity, 
a parameter associated with the capacity of the test to identify and separate the groups with different clinical outcomes; and clinical utility, a parameter associated with the capacity of a test to improve the clinical outcomes for the patients receiving the test compared to those for whom the test is not performed [4].

\section{MRD in Solid Tumors}

There is increasing evidence in support of measurable (minimal) residual disease (MRD), defined as a relatively small number of tumor cells that have survived the initial therapies (e.g., surgery when required, chemo-radiotherapy, etc.) and are present in extremely low levels undetectable in the morphological examination. The presence of MRD is a strong, independent, prognostic marker of increased risk of relapse and shorter survival. The detection of MRD using different experimental strategies and its treatment represent one of the most important topics in the research related to current and future cancer therapy [5]. The study of MRD in solid tumors requires the development of highly sensitive techniques capable of detecting even a few residual tumor cells [5].

The study of MRD in solid tumors became possible with the discovery that tumor cells circulate in the peripheral blood in the form of rare circulating tumor cells (CTCS). These CTCs release their DNA into the circulation, referred to as circulating tumor DNA (ctDNA), and it is possible to isolate and characterize this DNA $[5,6]$. The technologies currently used for the detection and characterization of CTCs in the blood samples of cancer patients, as well as the experimental and clinical studies based on CTC detection, were reviewed recently by Patel et al. [5]; these would not be analyzed in the present review. The approach of blood test-based detection of somatic mutations may provide extremely high specificity as this approach is based on the detection of specific driver mutations observed only in the tumor cells and not in the normal cells. The ctDNA analysis fulfills the three essential parameters of analytical validity, clinical validity, and clinical utility, and therefore represents a precious tool for the analysis of residual tumor cells remaining after the initial standard treatments [7]. Therefore, ctDNA analysis may enable performing a liquid biopsy of tumors, providing in part the information obtained with the tissue biopsy of tumors, using a procedure that is more convenient and less risky for the patients $[5,6]$. It is noteworthy that ctDNA may be present in the peripheral blood as cell-free DNA (cfDNA) or as the DNA contained in circulating extracellular vesicles such as exosomes (exoDNA). Interestingly, both cfDNA and exoDNA are present in the peripheral blood of healthy individuals as well.

Recent studies have reported detailed characterization of the cfDNA present in the blood of healthy individuals. The main sources of cfDNA are necrosis or apoptosis, and active release by viable cells through the processes such as exocytosis $[8,9]$. Therefore, it is not surprising that conditions associated with tissue damage and a pro-inflammatory environment may increase the release of circulating DNA in the blood $[8,9]$. Other factors that may influence the cfDNA levels are changes in blood components in relation to the circadian clock and food intake [10]. Circulating DNA may be derived from nuclear DNA or mitochondrial DNA or both. Interestingly, a recent study reported that a large proportion of circulating DNA is derived from the mitochondrial DNA in the form of genome copies; there were approximately 50,000-fold and 3,000-fold more mitochondrial genome copies compared to nuclear genome copies in the plasma of healthy individuals and metastatic colorectal cancer patients, respectively [11]. However, in terms of concentration $(\mathrm{ng} / \mathrm{mL})$, the levels of circulating nuclear DNA were higher than those of mitochondrial DNA [11]. 
Circulating DNA levels increase significantly with age in healthy individuals, while the same is not true for neoplastic patients [11].

Importantly, recent studies have demonstrated that with time, normal tissues accumulate somatic mutations that may induce the formation of various types of pre-neoplastic conditions, which lead to tumor development. The somatic mutations present in the pre-neoplastic clones may be released into cfDNA after cell apoptosis and may serve as a potential source of false positivity. A recent study explored the mutation profile of a large spectrum of cancer-related genes using nextgeneration sequencing and reported that $60 \%$ of the samples exhibited at least one nonsynonymous mutation [12]. In addition, for individuals aged above 50, the positive rate increased to $76 \%$. The most frequently mutated genes were the driver genes of hematologic malignancies, including DNMT3A, TET2, ASXL1, and JAK2. The remaining 58\% mutations were either passenger mutations of clonal hematopoiesis or certain other mutations, such as NOTCH2, FAT3, EXT2, ERBB4, and $A R I D 2$, which are driver mutations in solid tumors [12]. The presence of these mutations in both healthy cfDNA and neoplastic DNA could be the reason for false positives in ctDNA analyses, warranting the adoption of error correction models [12].

Multiple areas of oncology could benefit from liquid biopsies, including cancer diagnosis and prognosis, evaluation of MRD and risk of relapse, selection of optimal treatment, and monitoring of tumor burden [13].

Application of ctDNA analysis as a clinically feasible methodology requires developing techniques with high sensitivity and specificity. Even minute levels of ctDNA are now sufficient for performing the ctDNA analysis [14]. Detection of extremely low levels of circulating tumor DNA is achieved either through digital polymerase chain reaction (PCR) or by using error-corrected sequencing, a technique that usually includes molecular barcoding for the efficient recovery of circulating free DNA molecules and bioinformatics-based in-silico techniques to reduce the background artifacts $[15,16]$. The introduction of protocols based on barcoding single-strand DNA fragments enabled achieving an ultralow base error rate $(\leq 0.001 \%)$ in genomic DNA. Even better performance could be achieved with the use of duplex sequencing, a technology that utilizes information derived from the complementary strands of DNA molecules to correct the errors, allowing a base error rate as low as $<10^{9}[15,16]$. A position article by the American Society of Clinical Oncology highlighted the absolute requirement for standardization techniques and reporting, suggested conducting additional studies aimed at comparing the different assays used for the detection of ctDNA, and recommended the clinical use of ctDNA assay only in the context of clinical trials [17]. Proof of Principle studies have supported the potential clinical utility of ctDNA analysis in molecular profiling, prognostication, and monitoring, and the clinical application of this methodology has already begun [13].

The low sensitivity of liquid biopsy reported in several instances limits its utility in the detection of advanced-stage disease. In particular, patients with tumors at an early stage of development may harbor less than one mutant template molecule per milliliter of plasma, which is an extremely low level that is often undetectable in the techniques currently in use for the detection and evaluation of multiple mutations [18]. The limitations of the current assays could be evaded, in part, by combining the following two different strategies: (i) use of polymerase chain reaction-based assays that would concomitantly assess multiple regions of driver genes commonly involved in the pathogenesis of different cancer types, and are designed to maximally reduce the number of amplicons required to detect one driver gene mutation; (ii) performing ctDNA detection assay along with the evaluation of the levels of certain plasma proteins, such as cancer antigen 125 (CA-125), 
carcino-embryonic antigen (CEA), cancer antigen 19-9 (CA 19-9), prolactin (PRL), hepatocyte growth factor (GF), osteopontin (OPN), myeloperoxidase (MPO), and tissue inhibitor of metalloproteinases 1 (MIMP-1) [18]. This test, referred to as Cancer SEEK, was applied to 1,005 cancer patients with various non-metastatic cancer types. The test results were positive in $70 \%$ of these tumors. The sensibilities ranged from $67 \%$ to $98 \%$ for six different common cancers (ovary, liver, stomach, pancreas, esophagus, and colorectum). The Cancer SEEK test was able to define the cancer tissue origin in $83 \%$ of the cases. Only $1 \%$ of the normal individuals tested positive in the Cancer SEEK test [19].

Most of the efforts so far have been focused on enhancing the sensitivity of ctDNA technique. However, recent studies have explored the peculiar properties of ctDNA in comparison to the DNA released in circulation by normal cells. A few studies demonstrated certain important differences in the fragment lengths of the circulating DNA between tumor DNA and normal DNA. Muliere and coworkers demonstrated the enrichment of ctDNA in fragment sizes ranging between 90 and 150 base pairs; the fragment length of 90-150 bp enhanced the ctDNA detection, with a greater than two-fold median enrichment in a large majority of the cases and greater than 4-fold enrichment in $>10 \%$ of the cases [20]. This strategy improved the identification of ctDNA in purified samples from glioma, renal, and pancreatic cancer patients [19]. These findings were confirmed and extended by Cristiano et al., who developed a methodology for evaluating the fragmentation patterns of cellfree DNA across the genome, and observed that the cell-free DNA profiles of normal individuals largely presented nucleosomal patterns of white blood cells, while those of cancer patients presented altered DNA fragmentation patterns [21]. This methodology was applied to analyze the fragmentation profiles of patients with breast, colorectal, lung, ovarian, pancreatic, gastric, or bile duct cancers, and the data interpretation using a machine learning model revealed tumor detection sensitivities ranging from $57 \%$ to $99 \%$ in various cancer types. The combination of fragmentation profile evaluation and mutation-based analysis of cell-free DNA enabled achieving a detection rate of $91 \%$ in cancer patients [21].

The majority of the studies on solid tumors have been conducted with the specific aim of detecting molecular residual disease (MRD) after the completion of definitive therapy. This technique was applied successfully for MRD detection in several solid tumors, including colorectal cancer, breast cancer, lung carcinoma, pancreatic carcinoma, and nasopharyngeal carcinoma [22].

The pioneering study by Diehl et al. demonstrated the feasibility of ctDNA detection in a significant cohort of cancer patients [22]. The study also demonstrated that ctDNA in the plasma has a short half-life (of $<2 \mathrm{~h}$ ), although the ctDNA levels may be elevated $24 \mathrm{~h}$ following surgical tumor resection, apparently due to the release of ctDNA from the damaged tissue [23].

In this context, particularly significant were the studies performed in pancreatic, colorectal, breast, non-small cell lung, and prostate cancers, and melanomas, which are listed in Table 1.

Table 1 Clinical applications of ctDNA in the study of colorectal cancer, pancreatic cancer, melanoma, breast cancer, non-small cell lung cancer, and prostate cancer.

\begin{tabular}{lll}
\hline Cancer Type & ctDNA analysis & Clinical utility of ctDNA analysis \\
\hline \multirow{2}{*}{ CRC } & Analysis of KRAS, NRAS & Predictive biomarker for response to EGFR \\
(metastatic) & And BRAF mutations & $\begin{array}{l}\text { inhibitors, resistance to an EGFR inhibitor, } \\
\text { response monitoring monitoring disease }\end{array}$
\end{tabular}




\begin{tabular}{|c|c|c|}
\hline & & $\begin{array}{l}\text { progression and development of resistance } \\
\text { during the disease progression }\end{array}$ \\
\hline $\begin{array}{l}\text { CRC } \\
\text { (metastatic) }\end{array}$ & $\begin{array}{l}\text { Analysis of HER2 } \\
\text { amplification }\end{array}$ & $\begin{array}{l}\text { Predictive biomarker for response to dual- } \\
\text { targeted HER2-directed therapy }\end{array}$ \\
\hline $\begin{array}{l}\text { CRC } \\
\text { (stage II) }\end{array}$ & $\begin{array}{l}\text { Analysis of mutation } \\
\text { profile by ctDNA }\end{array}$ & $\begin{array}{l}\text { Determine the clinical impact of ctDNA analysis } \\
\text { to guide optimal therapy strategy }\end{array}$ \\
\hline $\begin{array}{l}\text { Pancreatic } \\
\text { cancer } \\
\text { (stages I-III) }\end{array}$ & ctDNA levels & $\begin{array}{l}\text { ctDNA levels are prognostic for disease } \\
\text { progression }\end{array}$ \\
\hline $\begin{array}{l}\text { Pancreatic } \\
\text { cancer } \\
\text { (stages III-IV) }\end{array}$ & ctDNA level & $\begin{array}{l}\text { ctDNA is predictive of recurrence after } \\
\text { chemotherapy }\end{array}$ \\
\hline $\begin{array}{l}\text { Pancreatic } \\
\text { cancer } \\
\text { (stages I/II) }\end{array}$ & $\begin{array}{l}\text { Short DNA fragments } \\
(<100 \mathrm{bp})\end{array}$ & $\begin{array}{l}\text { The selection of short fragments of plasmatic } \\
\text { DNA improves detection of ctDNA, } \\
\text { particularly of KRAS mutations }\end{array}$ \\
\hline $\begin{array}{l}\text { Melanoma } \\
\text { (metastatic) }\end{array}$ & $\mathrm{BRAF}^{\mathrm{V} 600 \mathrm{E}}, \mathrm{BRAF}^{\mathrm{V} 600 \mathrm{~K}}$ & $\begin{array}{l}\text { Clinical monitoring of the response to targeted } \\
\text { therapy and to immunotherapy }\end{array}$ \\
\hline $\begin{array}{l}\text { Melanoma } \\
\text { (metastatic) }\end{array}$ & NRAS mutations & $\begin{array}{l}\text { Identification of NRAS mutations as an early } \\
\text { biomarker of tumor evolution }\end{array}$ \\
\hline $\begin{array}{l}\text { Melanoma } \\
\text { (high-risk, stage } \\
\text { III) }\end{array}$ & levels & $\begin{array}{l}\text { Pre-operative ctDNA values are predictive of } \\
\text { overall survival }\end{array}$ \\
\hline $\begin{array}{l}\text { BC } \\
\text { (H-positive) }\end{array}$ & ESR1 mutations & $\begin{array}{l}\text { Resistance mechanism to endocrine therapy } \\
\text { (fulvestrant, exemestane) or to } \\
\text { everolimus; negative prognostic factor }\end{array}$ \\
\hline $\begin{array}{l}\text { BC } \\
\text { (H-positive) }\end{array}$ & PIK3CA mutations & Predictive biomarker for PIK3CA inhibitors \\
\hline $\begin{array}{l}\text { BC } \\
\text { (metastatic) }\end{array}$ & ctDNA genotyping & Identification of actionable alterations \\
\hline $\begin{array}{l}\text { NSCLC } \\
\text { (metastatic) }\end{array}$ & $\begin{array}{l}\text { Analysis of } \quad \text { EGFR } \\
\text { mutations } \\
\left.\text { EGFR }^{\mathrm{C7975}}\right)\end{array}$ & $\begin{array}{l}\text { Detection of resistance mechanisms to first-line } \\
\text { EGFR TKIs and to osimertinib }\end{array}$ \\
\hline $\begin{array}{l}\text { NSCLC } \\
\text { (metastatic) }\end{array}$ & $\begin{array}{l}\text { Analysis of ALK mutations } \\
\text { or CD74-ROS1 fusion or } \\
\text { ROS1 mutations }\end{array}$ & $\begin{array}{l}\text { Detection of resistance mechanisms to alectinib } \\
\text { treatment and response to ceritinib; resistance } \\
\text { mechanisms to crizotinib treatment }\end{array}$ \\
\hline $\begin{array}{l}\text { NSCLC } \\
\text { (Stages I-II) }\end{array}$ & $\begin{array}{l}\text { Analysis of patient- } \\
\text { specific mutational profile }\end{array}$ & $\begin{array}{l}\text { Molecular characterization of residual tumor } \\
\text { disease following primary lung cancer surgery }\end{array}$ \\
\hline $\begin{array}{l}\text { Prostate cancer } \\
\text { (metastatic) }\end{array}$ & $\begin{array}{l}\text { AR mutations, } A R \\
\text { amplification }\end{array}$ & $\begin{array}{l}\text { Detection of resistance mechanisms to } \\
\text { abitaerone and enzalutamide treatment }\end{array}$ \\
\hline $\begin{array}{l}\text { Prostate cancer } \\
\text { (metastatic) }\end{array}$ & ctDNA genotyping & $\begin{array}{l}\text { Identification of actionable genetic alterations in } \\
\text { castration resistant patients in progression }\end{array}$ \\
\hline $\begin{array}{l}\text { Prostate cancer } \\
\text { (metastatic) }\end{array}$ & $\begin{array}{l}\text { Homologous } \\
\text { recombination DNA } \\
\text { Repair defects }\end{array}$ & Predictive biomarkers for PARP inhibitors \\
\hline
\end{tabular}




\section{CtDNA in Pancreatic Cancer}

Pancreatic ductal adenocarcinoma (PDAC) is the most lethal of the common cancers, and with a five-year survival rate of $<10 \%$, it is currently the fourth most common cause of cancer-related deaths [24]. Whole-genome sequencing and deep-exome sequencing studies have demonstrated that pancreatic cancer is a heterogeneous disease, characterized by frequent mutations in KRAS in $92 \%$ of the cases, cell-cycle checkpoint mutations (TP53, CDKN2A) in $72 \%$ of the cases, alterations in various genes involved in TGF- $\beta$ signaling in $47 \%$ of the cases, and mutations in the genes involved in histone modification in $24 \%$ of the cases [25]. KRAS is the best characterized tumor-related gene in pancreatic cancer, and most of the mutations detected in this gene are located at the level of codon 12. Therefore, the KRAS mutant has become the most-explored tumor marker in ctDNA studies.

The relevant studies conducted with pancreatic cancer patients are summarized in Table 2 . The large majority of these studies involved patients with advanced disease and were based on the detection of KRAS mutations in ctDNA, presenting good sensitivity and specificity. The presence of detectable ctDNA, at baseline or postoperative, in resectable pancreatic cancer patients was significant for the prognosis of disease recurrence and the overall survival. A few relevant studies were based on the analysis of DNA methylation in ctDNA and corroborated the prognostic and diagnostic utility of the ctDNA assay [24-40].

Table 2 Main studies on ctDNA analysis in pancreatic cancer patients.

\begin{tabular}{|c|c|c|c|}
\hline Authors & $\begin{array}{l}\text { Sample size } \\
\text { (patients) }\end{array}$ & Design & Results/Conclusions \\
\hline $\begin{array}{l}\text { Sausen et } \\
\text { al. [26] }\end{array}$ & 51 & $\begin{array}{l}\text { Patents } \\
\text { with } \\
\text { localized } \\
\text { disease }\end{array}$ & $\begin{array}{l}43 \% \text { of patients were positive for mutKRAS ctDNA. The } \\
\text { patients with detectable ctDNA after surgical resection } \\
\text { were more likely to relapse compared with those with } \\
\text { undetectable ctDNA. }\end{array}$ \\
\hline $\begin{array}{l}\text { Cohen et } \\
\text { al. [27] }\end{array}$ & 221 & $\begin{array}{l}\text { Patients } \\
\text { with } \\
\text { resectable } \\
\text { pancreatic } \\
\text { cancer } \\
\text { (stages I and } \\
\text { II) }\end{array}$ & $\begin{array}{l}\text { The Authors observed KRAS mutation in the plasma of } \\
30 \% \text { of these patients, with a } 100 \% \text { concordance with } \\
\text { the mutation type observed in patient's primary tumor; } \\
\text { the combined use of ctDNA assay and together with } \\
\text { detection of four protein biomarkers increased the } \\
\text { sensitivity to } 64 \% \text {. The positivity of plasma ctDNA was } \\
\text { associated with a negative outcome. Exosomes may be } \\
\text { used as an alternative source, which is complementary } \\
\text { to other liquid biopsy DNA sources. }\end{array}$ \\
\hline $\begin{array}{l}\text { Allenson } \\
\text { et al. [28] }\end{array}$ & 88 & $\begin{array}{l}\text { Patients } \\
\text { with } \\
\text { pancreatic } \\
\text { cancer at all } \\
\text { stages }\end{array}$ & $\begin{array}{l}\text { The Authors have compared the evaluation of } K R A S \\
\text { mutations in cfDNA and exoDNA in a group of all-stages } \\
\text { pancreatic cancer patients: KRAS mutations in exoDNA } \\
\text { were identified in } 7 \%, 66 \%, 80 \% \text { and } 85 \% \text { of age- } \\
\text { matched controls, localized, locally advanced and } \\
\text { metastatic pancreatic cancer patients; comparatively, } \\
\text { mutant } K R A S \text { cfDNA was detected in } 14 \%, 45 \%, 31 \% \\
\text { and } 58 \% \text { of these individuals. ExoDNA seems to be a }\end{array}$ \\
\hline
\end{tabular}




$\begin{array}{lll}\text { Kruger et } & & \text { with } \\ \text { al. [29] } & 54 & \text { advanced } \\ & & \text { disease } \\ & \text { receiving } \\ & \text { gemcitabine }\end{array}$

Kim et al. 106

210

al. [31]

$\begin{array}{lll}\text { Bernard } & 34 & \text { with } \\ \text { et al. [32] } & 34 & \begin{array}{l}\text { localized } \\ \text { disease }\end{array}\end{array}$

Wei et al.

[33]

\section{5}

Sugimori

\section{7} with advanced disease

Patients with advanced disease

Patients with disease

Patients with advanced disease

Patients with advanced

better source than cfDNA to assess KRAS mutational status.

The authors explored mutKRAS ctDNA, CA 19-19, CVEA,

Patients

with and CYFRA 21-1 in 54 patients receiving gemcitabinebased chemotherapy. MutKRAS ctDNA was present in $67 \%$ of these patients and showed a status of tissue KRAS mutation with a sensitivity of $75 \%$ and specificity of $100 \%$. During therapy, changes in mutKRAS ctDNA levels showed more rapid and pronounced changes and predicted better progressive disease than proteinbased markers.

The authors evaluated ctDNA in patients with advanced pancreatic cancer though multiplex detection of KRAS Patients mutations in plasma samples. KRAS mutations were disease detected in $96 \%$ of tissue samples and in $80.5 \%$ of ctDNA. KRAS mutation concentration and KRAS fraction were predictors for PFS and OS; when combined withCA19-9, the KRAS mutation concentration in ctDNA was more predictive of OS.

The authors explored mutKRAS ctDNA in 210 patients with advanced pancreatic cancer: KRAS G12V was mutated in 29 and KRAS ${ }^{G 12 V}$ in 44\% of cases. MutKRAS ctDNA positivity correlated with OS. KRAS ${ }^{G 12 V}$ mutation in ctDNA correlated with Treg and patients doublepositive have a poor prognosis.

The authors measured the KRAS mutational burden in ctDNA and exoDNA at baseline and during therapy. Their results showed that: patients with metastases and detectable ctDNA at baseline displayed shorter times of disease progression and OS; a mutant KRAS mean allele frequency of $\geq 5 \%$ in exoDNA is a significant predictor of PFS and OS; detection of both ctDNA and exoDNA at baseline predicts OS on multivariate analysis.

The authors explored the mutational profile by NGS in plasma DNA: about $66 \%$ of patients displayed at the level of ctDNA at least one common driver gene alteration; allele fraction for mutated genes declined in chemotherapy-responsive patients.

The authors explored the dynamics of KRAS mutations in 47 pancreatic cancer patients undergoing treatment with chemotherapy. At the tissue level, $96 \%$ of patients displayed KRAS mutations in ctDNA (with a MAF from 
$0.1 \%$ to $31 \%$ ). ctDNA monitoring enabled disease assessment and predicted PFS.

Groot et 58
al. [35]

Mohan et

al. [36]

55

Henriksen

et al. [37]

95

Henriksen

et al. [38]

Eissa et

al. [39]
95

173
Patients with locally advanced disease

55 patients:

31

metastatic, 24 with

locally advanced disease

Patients with pancreatic cancer at all stages

Patients The authors analyzed DNA promoter hypermethylation with in a panel of selected genes from cfDNA. The cfDNA pancreatic promoter hypermethylation pattern is a prognostic cancer at all marker in that it enables the differentiation of stages

Patients with pancreatic cancer at all stages

The authors explored for mutKRAS ctDNA in 58 patients with locally advanced pancreatic cancer undergoing neoadjuvant chemotherapy and surgery debulking. Of patients, $49 \%$ have positive mutKRAS ctDNA before therapy and this positivity correlated with reduced RFS and OS. mutKRAS ctDNA positivity post-neoadjuvant chemotherapy correlated with poor prognosis; postoperative and during follow-up mutKRAS ctDNA positivity predicted disease relapse.

The authors determined the NGS mutational profile in ctDNA of 55 pancreatic cancer patients: mutations in ctDNA were observed in $62.5 \%$ of patients with locally advanced disease and in $87 \%$ of those with metastatic disease; the presence of mutations in ctDNA was associated with the worse outcome; $12.5 \%$ of patients displayed gain of chromosome $12 p$ harboring KRAS in their ctDNA.

The authors analyzed DNA promoter hypermethylation in a panel of selected genes from cfDNA. The results showed that cfDNA promoter hypermethylation has the potential to be a diagnostic marker for pancreatic cancer and differentiates between malignant and benign pancreatic disease. pancreatic cancers according to stage.

The authors investigated the profile of promoter methylation of BNC1 and ADAMTS1 genes using ctDNA. By exploring the two combined markers, overall sensitivity of the assay was $87 \%$, and specificity was $85 \%$. 


\begin{tabular}{lll} 
Patients & $\begin{array}{l}\text { based on the combination of cfDNA analysis (cfDNA } \\
\text { concentration, and mutKRAS in cfDNA), extracellular }\end{array}$ \\
Yang etal. 54 & $\begin{array}{l}\text { pancreatic } \\
\text { cancer at all } \\
\text { stages }\end{array}$ & $\begin{array}{l}\text { vesicles mRNA and miRNA profile and CA19-9 } \\
\text { detection. The multianalyte biomarker assay improved } \\
\text { pancreatic cancer diagnostic accuracy and might have } \\
\text { helped in the pre-operative identification of non- } \\
\text { metastatic patients best suited for surgery. }\end{array}$ \\
\hline
\end{tabular}

Recent studies have provided evidence that consistent improvement in the detection of ctDNA in the plasma of pancreatic cancer patients is possible through the analysis of short DNA fragments. Liu and coworkers reported developing a single-strand library preparation and hybrid-capturebased ctDNA sequencing (SLHS-seq) approach. The procedure was applied to perform cfDNA profiling in a group of 112 pancreatic cancer patients, and the results demonstrated high specificity and sensitivity in the detection of ctDNA in pancreatic cancer patients, including those at an early stage of disease [41]. Indeed, using this approach, ctDNA could be detected in $88 \%$ of stage $1 / 11$ pancreatic adenocarcinoma cases and in 95\% of those with stage III/IV disease [41]. The analysis of cfDNA fragment size revealed that the DNA fragments that contained the wild-type KRAS allele were all around $160 \mathrm{bp}$ in size, while a large proportion of the DNA fragments containing the mutant KRAs allele had size below 100 bp [41]. Interestingly, the short DNA fragments were more pronounced in the pre-cancerous stage and in early-stage pancreatic cancers [38]. These results were corroborated by the findings of another study that analyzed 40 plasma DNA samples derived from pancreatic cancer patients who were known to carry a KRAS mutation [42]. These cell-free DNA samples were re-screened using 4-size (57 bp, 79 bp, 167 bp, and 218 bp) amplicons strategy in combination with ultra-deep sequencing [39], and the results revealed that the shorter the amplicon size, the higher was the mutant allelic fraction; consequently, the proportion of cases with detectable KRAS mutations increased by a factor of two for the amplicons shorter than $80 \mathrm{bp}$ compared to those shorter than 218 bp [42].

Interestingly, a recent phase I clinical study (NCT 12368860), which was being conducted with patients having advanced pancreatic cancer and undergoing treatment with oxaliplatin, capecitabine, and irinotecan (OXIRI) triplet chemotherapy, included ctDNA analyses in its design [43]. In this clinical study, an amplicon-based NGS approach was used for ctDNA evaluation, which utilized a targeted panel with error-correction to detect mutant KRAS, TP53, SMAD4, CDKN2A, CTNNB1, GNAS, APC, and MYC. Using this approach, ctDNA was detected in $83 \%$ of the patients at baseline, which included mutations in KRAS (73\%), TP53 (61\%), SMAD4 (48\%), and CDKN2a (30\%) [43]. A drop in the levels of ctDNA and CA19-9 following therapy was reported to be associated with a longer PFS, while lower ctDNA levels were associated with partial radiological response. The comutation of KRAS and SMAD4 was associated with poor prognosis [43]. A clinical trial (NCT 02934984), which is currently under progress, is evaluating the factors associated with pancreatic cancer recurrence using cfDNA analysis, with an additional objective of studying the correlation between cfDNA and the clinical outcome of pancreatic cancer. 


\section{CtDNA in Colorectal Cancer}

Colorectal cancer (CRC) is the third most common cancer in the world [44]. In several patients, the development of CRC is preceded by a benign neoplastic lesion, either in the adenomatous polyp or in a serrated polyp [44]. Studies characterizing the molecular alterations occurring in CRCs have demonstrated that each CRC patient exhibits around two to eight driver mutations [44]. The Cancer Genome Atlas (TCGA) has provided a comprehensive molecular characterization of CRCs [45], the major findings of which include: (i) approximately $16 \%$ of these cancers (CRCs) presented hypermutation, which is associated with high microsatellite instability in $75 \%$ of the cases and with mutations of polymerase epsilon and mismatch repair genes in $25 \%$ of the cases; (ii) nonhypermutated cancers exhibited recurrent mutations in a considerable number of genes, including APC, TP53, SMAD4, PI3KCA, KRAS, SOX9, FAM123B, and ARID1A; (iii) in the hypermutated cancers, the most frequently mutated genes were ACVR2A, APC, TGFBR2, BRAF, MSH3, MSH6, MYO18, TCF7L2, and CASP8; among these, the APC and TP53 genes were significantly more mutated in the non-hypermutated cancers compared to hypermutated cancers [45].

Initial studies conducted with a limited number of patients have supported the clinical utility of ctDNA evaluation in CRC patients. A pilot study conducted by Reinert and coworkers employed digital droplet PCR to evaluate the levels of ctDNA in several plasma samples obtained from six relapsing and five non-relapsing CRC patients, and correlated these explorations to the clinical findings. In particular, an efficient assessment of disease status, response to surgery or oncological treatments, and early detection of incipient recurrent disease was demonstrated with the use of this approach [46]. Scholer et al. longitudinally explored 27 patients undergoing surgical resection for $C R C$, and reported positive ctDNA detection in all the 14 patients exhibiting relapse, while no detection was reported for the non-relapsing patients [47]. Tie and coworkers performed ctDNA analysis in 230 patients with stage II CRC who were undergoing surgical resection and those who were undergoing adjuvant chemotherapy, and reported detecting ctDNA postoperatively in $7.9 \%$ of the patients, among which $79 \%$ exhibited recurrence at the median follow-up of 27 months, while recurrence occurred in only $9.8 \%$ of the patients who had tested negative for ctDNA postoperatively [48].

Early-stage detection of CRC using tumor-derived cfDNA is challenging as only a small proportion of cfDNA is derived from the tumor tissue in early-stage disease. In order to address this issue, Wan et al. adopted a machine learning approach to differentiate between the signatures in cfDNA, which were reflective of tumor contributions and those which were reflective of non-tumor contributions [49]. Using this approach, a sensitivity of $85 \%$ in the detection of early-stage (stage I/II) colorectal cancers was achieved [49]. Phallen et al. reported positive detection of ctDNA in $71 \%$ of the tested stage I/II CRC patients [50]. Yang et al. compared ctDNA detection in early-stage and late-stage CRC patients, and reported that ctDNA was detectable in $>90 \%$ of the cases in both early-stage and latestage patients [51]. The late-stage patients exhibited a significantly higher ctDNA concentration compared to the stage I/II patients, and the increased ctDNA concentration was correlated with increased tumor size [51].

Interestingly, two recent studies explored the prognostic potential of ctDNA assay in postoperative surveillance of non-metastatic CRC patients. Among these, the study by Wang et al. explored the prognostic impact of ctDNA measurements in the postoperative surveillance of a group of 58 patients with stage I-II-III CRC undergoing surgical detection [55]. The recurrence rate among 
the patients with positive ctDNA was high (77\%), and in these patients, ctDNA positivity preceded the radiological and clinical evidence of recurrence by a median of three months [52]. None among the 45 patients with negative ctDNA presented disease relapse [52]. In particular, 13 of the total 48 patients tested positive for ctDNA after treatment, and among these 13 patients, 10 relapsed, while the three who did not relapse had positive ctDNA earlier, which later [after treatment] dropped to undetectable levels [52]. Among the 40 patients who did not receive chemotherapy, eight presented disease recurrence after testing positive for ctDNA, although only five of these patients exhibited positivity for CEA. Among the 18 patients who received chemotherapy, two patients who had tested positive for ctDNA relapsed later, although only one of these two patients exhibited positivity for CEA [52]. In the other study, Reinert and coworkers investigated the association of circulating tumor DNA with disease recurrence using longitudinal data obtained from ultra-deep sequencing of plasma cell-free DNA in patients with CRC prior to and after surgery, during and after adjuvant chemotherapy, and during surveillance [53]. Importantly, this study was conducted with 130 stage I-II-III CRC patients who were monitored prior to surgery as well as postoperatively at Day 30 and then every third month up to three years [53]. Pre-operatively, ctDNA was detectable in $89.4 \%$ of the patients, while after definitive treatment, it was detected in $87.5 \%$ of the relapsing patients. On postoperative day 30, the ctDNA-positive patients exhibited a 7-times increased probability of relapse compared to the ctDNA-negative patients. All the patients who tested ctDNApositive after adjuvant chemotherapy exhibited relapse. Finally, during surveillance after definitive therapy, the ctDNA-positive patients exhibited greater than 40 times increased probability of relapse compared to the ctDNA-negative patients [53].

Several studies have explored ctDNA as a marker of therapeutic response to systemic treatments in CRC patients with advanced or metastatic disease. Tie et al. evaluated a group of 52 metastatic CRC patients treated with standard first-line chemotherapy and reported the detection of ctDNA in $92 \%$ of these patients. In addition, significant reductions (approximately 5-7 folds) in ctDNA levels were observed prior to commencing cycle 2 of chemotherapy, which correlated with radiology imaging. Furthermore, major reductions observed in the ctDNA levels at cycle 2 of chemotherapy were associated with a tendency to exhibit increased progression-free survival [54].

Three independent studies reached the same conclusion that ctDNA positivity is a suitable marker for the prediction of disease recurrence in stage III CRC patients. In the first study, Tie and coworkers conducted a longitudinal analysis in a cohort of 159 patients with clinically-advanced rectal cancer who were undergoing neo-adjuvant chemo-radiotherapy prior to surgical resection, and in this analysis, ctDNA was assayed pre-treatment (77\% positivity), post-chemo-radiotherapy (8.3\% positivity), and after surgery ( $12 \%$ positivity) [55]. The detection of ctDNA after chemoradiotherapy or after surgery was associated with short recurrence-free survival (RFS): the 3-year RFS was $33 \%$ in the patients who tested positive for ctDNA after surgery and $87 \%$ in the patients who tested negative for ctDNA after surgery [55]. In the second study, Tie and coworkers reported that in a group of stage III CRC patients, ctDNA was positive in $21 \%$ of the post-surgical samples, and was associated with shorter recurrence-free survival. The ctDNA was detectable in $17 \%$ of the patients after chemotherapy: the relapse-free index with a 3-year follow-up was $30 \%$ in the patients with detectable ctDNA after chemotherapy and $77 \%$ in those with undetectable ctDNA after chemotherapy [56]. In the third study, Tarazona and coworkers performed ctDNA analysis in a population of patients with locally advanced colorectal cancer; the tumors of these patients were analyzed using next-generation sequencing, and their main genetic abnormalities were determined. 
The tracking of at least two variants was reported to improve the MRD detection efficiency to $87.5 \%$ [57]. The ctDNA was the only significant independent predictor of disease-free survival in the multivariate analysis [57]. Importantly, in the patients treated with adjuvant chemotherapy, the presence of ctDNA after therapy was reported to be associated with early recurrence [57]. Furthermore, the positivity of ctDNA preceded the radiological recurrence by approximately 11.5 months [57].

Several recent studies have also explored ctDNA in metastatic CRC patients. The initial studies demonstrated that ctDNA was detectable in almost all the metastatic CRC patients and that the ctDNA levels reflected tumor burden. Furthermore, the ctDNA levels were reported to increase in the patients with disease progression, while the levels decreased in the patients responding to treatments [58]. Interestingly, in a screening of ctDNA detection in various metastatic cancers, colorectal cancer emerged as the tumor for which ctDNA detection was the highest [59]. In colorectal tumors, the levels of variant allele frequency detected in the ctDNA were the predictors of worse prognosis [59].

Two studies reported the evaluation of ctDNA levels in metastatic CRC patients in response to chemotherapy. Among these, Osumi and coworkers investigated the clinical impact of early changes in the ctDNA levels as a predictor of the response and clinical outcome, in metastatic CRC patients who received treatment with chemotherapy, and reported that the patients with lower ctDNA levels after the initiation of chemotherapy exhibited significantly longer PFS and OS compared to the patients with higher ctDNA levels [60]. A similar conclusion was reached by the other study, in which Lyskjaer and coworkers investigated the early changes in the ctDNA levels following treatment with FOLFIRI chemotherapy. The patients with higher pre-treatment levels of ctDNA or cfDNA were reported to exhibit significantly shorter PFS compared to the patients with lower ctDNA or cfDNA levels, while the patients exhibiting temporary increases in the ctDNA levels during the treatment had shorter PFS and OS [61].

In the studies that have reported ctDNA analysis in metastatic CRC patients, three different approaches have been used: (i) in the studies that involved analysis of a few mutations, such as RAS or BRAF mutations, the assays were based on PCR analysis, for example, the use of BEAMing or droplet digital PCR to detect mutations with extremely low mutant allele fraction; (ii) targeted NGS panel was utilized for the detection of multiple mutations, although with lower sensitivity compared to PCR; (iii) whole-exome or whole-genome sequencing was used, in which the amplitude of genomic coverage is achieved at the expense of depth of coverage [62]. Therefore, the application of ultra-deep targeted sequencing using digital droplet PCR was able to improve the capacity of detecting cfDNA somatic alterations with a variant allele frequency as low as $0.18 \%$ [63]. On the contrary, the application of next-generation sequencing lowered the detection sensitivity, as evidenced by the study reported by Furuki and coworkers, who analyzed the sensitivity of liquid biopsies in detecting mutations in liver tumor metastases in CRC patients and reported a sensitivity of $64 \%$ with the use of NGS and $89 \%$ with the use of digital PCR [64].

The analysis of KRAS mutation in ctDNA using BEAMing prior to first-line or second-line treatments, particularly the evaluation of mutant allele fraction (MAF), revealed a prognostic value; the patients with low MAF at baseline exhibited better PFS and OS [65]. Since testing for activating KRAS or NRAS mutations is essential for the selection of patients who could benefit from targeted anti-EGFR therapy, it is not surprising that most of the studies concerning the monitoring of metastatic CRC patients using ctDNA assays were focused on analyzing the RAS mutational status 
[66-72]. One of the main clinical utilities emerging from the use of ctDNA assay is the assistance provided in the identification of patients with a low number of mutant RAS cells who could nevertheless benefit from targeted anti-EGFR therapy. Indeed, the monitoring of RAS mutations is fundamental for the appropriate selection of patients who could benefit from anti-EGFR treatment, as RAS mutations are key determinants of resistance to treatment. Similarly, the presence of $B R A F^{V 600 E}$ is a factor representing resistance to anti-EGFR therapy. Using a sensitive assay, Thierry and coworkers demonstrated that the efficiency of analysis of the mutational profiles of KRAS, $N R A s$, and BRAF achieved using ctDNA analysis and tumor-tissue analysis was similar, suggesting that ctDNA analysis could replace tumor-tissue analysis [73].

A study of the ctDNA mutational profile in metastatic CRC patients undergoing treatments with therapeutic regimens, including anti-EGFR monoclonal antibodies, provided assistance in understanding the mechanisms of resistance to treatments [74]. In a phase II study based on the administration of irinotecan and anti-EGFR mAb panitumumab to metastatic CRC patients, Siena et al. demonstrated that the ctDNA analysis of the emergence of RAS mutations presented a rate of $36.7 \%$, which was much higher compared to the rate of $9.5 \%$ achieved with the tumor-tissue analysis of RAS mutations, suggesting a higher sensitivity of tumor mutational profile detection for ctDNA analysis compared to tissue mutational testing [75].

Various mechanisms that are responsible for resistance to EGFR inhibitors in the CRC cells might be innate or acquired. The application of the ctDNA technology has provided consistent assistance in the monitoring of the kinetics, in defining the nature of the acquired resistance, and in undertaking decisions related to the treatment of relapsing patients [76]. Longitudinal ctDNA surveillance in the CRC patients undergoing treatment with EGFR blocking agents enabled the detection of the emergence of RAS mutations through the analysis of plasma obtained after the anti-EGFR therapy [77, 78]. Furthermore, longitudinal monitoring using NGS-based ctDNA assay performed during anti-EGFR therapy enabled the identification of the emergence of acquired RAS mutations, as well as the detection of alterations in the other genes, such as MET, ERBB2, FLT3, EGFR, and MEK [79].

In particular, ctDNA analysis contributed to the development of re-challenge therapy, which is based on the observation that a transient withdrawal of anti-EGFR mAb results in a decline of RASresistant clones that lack growth advantage relative to the other clones, and that re-challenge of these tumors results in a restoration of their sensitivity to anti-EGFR inhibition [80]. A phase II study conducted by Cremolini and coworkers demonstrated the role of ctDNA analysis in guiding the development of a re-challenge strategy. The study involved performing re-challenge in the CRC patients with RAS-WT and in the BRAF-WT metastatic CRC patients who developed resistance to first-line cetuximab and irinotecan. The results revealed that none of the six patients responding to anti-EGFR re-challenge had a RAS mutation in their ctDNA, and this effect resulted in an increased PFS in the patients with RAS-WT ctDNA compared to the patients with RAS-mutated ctDNA (4 months vs. 1.7 months) [81]. In order to further corroborate this strategy, a clinical trial (NCT03227926; Rechallenge with panitumumab driven by RAS dynamic of resistance) currently under progress is evaluating the efficacy of panitumumab re-challenge when the RAS mutation load in ctDNA exhibits a decrease of $>50 \%$ compared to the levels observed at the moment of progression (Table 3) [82].

BRAF mutations occur in approximately $10 \%-12 \%$ of CRC patients. In particular, approximately $10 \%$ of the metastatic CRC patients exhibit BRAF ${ }^{V 600 E}$ mutations. A further rare group of patients, 
corresponding to $2 \%$ of the metastatic colorectal cancer patients exhibit $B R A F^{\text {nonV600E }}$ mutations. The $B R A F$ mutations detected in CRC patients are subdivided into three classes: class 1 , which involves the activation of RAS-independent signaling through monomers, such as BRAF ${ }^{V 600 E}$; class 2, involving codons 597/601, which activate RAS-independent signaling as dimers; and class 3 , involving codons 594/596, which are RAS-dependent with impaired kinase activity [83]. Unique clinical and pathological characteristics are observed in colorectal cancers with any of these three different types of BRAF mutants [83]. BRAF ${ }^{V 600}$ mutant-bearing CRCs are associated with poor prognosis and limited response to standard treatments, while the prognosis appears to be better in $B R A F^{n O n V 600 E}$ mutant-bearing colorectal cancers, particularly those bearing class $3 B R A F$ mutants [83]. In a study, ctDNA assay was utilized to detect the $B R A F$ mutation status in patients undergoing treatment with EGFR blocking agents [84].

Observation of amplification and/or overexpression of HER2 is reported in approximately $3 \%$ of the patients with CRC. HER2 is a predictive biomarker and treatment target in CRC [88]. Several retrospective studies have suggested that $H E R 2$ amplification could serve as a predictive biomarker of resistance to anti-EGFR in the patients with mutated RAS and wild-type BRAF bearing CRCs [89], while certain other studies suggest disease stabilization using this treatment [90]. HER2 was explored as a therapeutic target in metastatic colorectal cancer. In this context, the HERACLES-A study supported the use of a dual HER2-targeted therapy (using trastuzumab and lapatinib) in the CRC patients refractory to standard treatments such as cetuximab and panitumumab, demonstrating complete responses in $6 \%$ of the cases and partial responses in $24 \%$ of the cases [ 88 , 89]. Interestingly, pre-treatment and post-progression plasma samples of the patients participating in the HERCULES A study were subjected to evaluation of HER2 copy number in cfDNA, and the patients with $\geq 25.8$ HER2 copies in their CfDNA were the ones exhibiting best benefit from the treatment [90]. Nakamura et al. utilized liquid biopsy to investigate whether HER2 amplification could represent an acquired anti-EGFR therapy resistance mechanism, and observed that HER2 amplification was were identified after therapy in $5.5 \%$ of the metastatic CRC patients undergoing treatment with anti-EGFR agents; these patients exhibited a low median HER2 copy number of approximately 4, not amenable to the current anti-HER-targeted treatments [91]. Moreover, the MyPathway clinical trial provided evidence that the patients naive to the anti-EGFR therapy presented better responses with the use of dual-targeted HER2-directed therapy (using trastuzumab and pertuzumab) compared to the patients who had been receiving prior anti-EGFR treatments [92].

Encouraging results were obtained in several clinical studies which are currently under progress and involve dual HER2 blockade in metastatic CRC patients with HER2 amplification: the TRIUMPH study involving treatment with trastuzumab plus pertuzumab; the MOUNTAINEER trial involving treatment with tucatinib plus trastuzumab; and the HERACLES-B study concerning the combination of pertuzumab with trastuzumab emtansine. Interestingly, in the TRIUMPH study, the treatmentrefractory RAS wild-type metastatic CRC patients with HER2 amplification confirmed by tissue or ctDNA analysis received treatment with two HER2 inhibitors-trastuzumab and pertuzumab (Table 3), and among them, $35 \%$ in the tissue-positive group and $33 \%$ in the ctDNA-positive group responded to the treatment [93]. This finding corroborates the application of ctDNA assay as a suitable tool for selecting patients who could benefit from dual HER2 targeting [93].

A study reported that HER2 mutations were more frequent in KRAS-negative CRC patients (14\%) compared to KRAS-negative (4.4\%) CRC patients [94]. 
Table 3 Ongoing ctDNA-based clinical trials in CRC patients.

\begin{tabular}{|c|c|c|c|c|c|}
\hline $\begin{array}{l}\text { Trial identification } \\
\text { (sponsor) }\end{array}$ & Clinical phase & Title & Disease and objectives & Drugs & Status \\
\hline $\begin{array}{l}\text { NCT02980510 } \\
\text { (UNICANCER) }\end{array}$ & $\begin{array}{l}\text { Phase II, } \\
\text { randomized }\end{array}$ & $\begin{array}{lr}\text { Comparison } & \text { FOLFIRINOX, } \\
\text { Panitumumab r } & \text { vs. } \\
\text { mFOLFOX6, Panitumumab } \\
\text { in RAS/BRAF } & \text { wild-type } \\
\text { metastatic } & \text { colorectal } \\
\text { cancer } & \text { patients } \\
\text { (PANIRINOX) } & \end{array}$ & $\begin{array}{l}\text { Metastatic CRC, KRAS, NRAS and BRAF-WT } \\
\text { tumor status according to } \\
\text { plasma analysis of circulating DNA by Intplex } \\
\text { Technology } \\
\text { Main objective: evaluation of complete } \\
\text { response rate on treatment } \\
\text { combining FOLFIRINOX and Panitumumab }\end{array}$ & $\begin{array}{l}\text { mFOLFOX6+panit } \\
\text { umumab } \\
\text { vs. } \\
\text { FOLFIRINOX+pani } \\
\text { tumumab }\end{array}$ & $\begin{array}{l}\text { Active } \\
\text { Recruitin } \\
\text { g }\end{array}$ \\
\hline $\begin{array}{l}\text { NCT03227926 } \\
\text { (Fondazione del } \\
\text { Piemonte } \\
\text { Per l'Oncologia) }\end{array}$ & $\begin{array}{l}\text { Phase II, } \\
\text { open label, } \\
\text { single arm }\end{array}$ & $\begin{array}{l}\text { Re-challenged with } \\
\text { pertuzumab driven by } \\
\text { RAS dynamic of resistance } \\
\text { (CHRONOS) }\end{array}$ & $\begin{array}{l}\text { Metastatic CRC with subsequent decay of RAS } \\
\text { mutant clones } \\
\text { Main objective: to assess whether a third line } \\
\text { re-challenge with } \\
\text { panitumumab may achieve ORR of } 30 \% \text { or more } \\
\text { in a population } \\
\text { of RAS-WT mCRC selected on the basis of RAS } \\
\text { extended clonal evolution } \\
\text { in their plasma as evaluated by ctDNA } \\
\text { determination }\end{array}$ & Panitumumab & $\begin{array}{l}\text { Active } \\
\text { Recruitin } \\
\text { g }\end{array}$ \\
\hline $\begin{array}{l}\text { NCT03087071 } \\
\text { (M.D. Anderson } \\
\text { Cancer } \\
\text { Center) }\end{array}$ & Phase II & $\begin{array}{l}\text { Panitumumab with or } \\
\text { without trametinib in } \\
\text { treating patients with } \\
\text { stage IV colorectal cancer }\end{array}$ & $\begin{array}{l}\text { Metastatic CRC defined according to } \\
\text { RAS/BRAF/EGFR } \\
\text { mutation status }\end{array}$ & $\begin{array}{l}\text { Panitumumab vs. } \\
\text { panitumumab } \\
+ \text { trametinib }\end{array}$ & $\begin{array}{l}\text { Active } \\
\text { Recruitin } \\
\mathrm{g}\end{array}$ \\
\hline $\begin{array}{l}\text { UMIN000027887 } \\
\text { (National Cancer } \\
\text { Center Hospital } \\
\text { East) }\end{array}$ & Phase II & $\begin{array}{l}\text { Multicenter phase II study } \\
\text { to evaluate } \\
\text { efficacy and safety of } \\
\text { combination therapy with }\end{array}$ & $\begin{array}{l}\text { Metastatic CRC with ERBB } 2 \text { amplification } \\
\text { Main objective: to evaluate the efficacy and } \\
\text { safety of the combination therapy }\end{array}$ & $\begin{array}{l}\text { Trastuzumab } \\
\text { pertuzumab }\end{array}$ & $\begin{array}{l}\text { Active } \\
\text { Recruitin } \\
\mathrm{g}\end{array}$ \\
\hline
\end{tabular}




\section{ACTRN126150003 Phase II}

\section{3}

(National Health

and Medical

Research Council)

ACTRN126170015 Phase II/III

\section{5}

(National Health

and Medical

Research Council)

\section{NTC03844620}

Phase II

(M.D. Anderson

Cancer

Center) trastuzumab

and with trastuzumab and pertuzumab in patients

pertuzumab

with

metastatic

cancer

\section{Circulating tumor DNA Stage II CRC}

(ctDNA) informing Main objective: to investigate how ctDNA could adjuvant chemotherapy in stage II colon cancer (DYNAMIC II) stage II CRC

inform adjuvant chemotherapy

Circulating tumor DNA Stage III CRC locally recurrent or locally (ctDNA) informing advanced CRC subdivided in arm A

adjuvant chemotherapy in randomly receiving either standard stage III colon cancer: a chemotherapy or treatment according

multicenter phase $\mathrm{II} / \mathrm{III}$ to ctDNA results) and arm B (patients with randomized

controlled

trial

(DYNAMIC III)
escalation adjuvant chemotherapy and patients with negative ctDNA results

will receive a de-escalation adjuvant chemotherapy).

Main objective: to investigate whether escalation or de-escalation treatment

Strategies as informed by postoperative ctDNA assay will affect RFS.

Circulating cell-free tumor Stage III/IV advanced/metastatic CRC

DNA testing in guiding treatment for patients with advanced or metastatic colorectal pati cancer
Main objective: to evaluate the capacity of ctDNA testing to monitor the response and to guide treatment with regorafenib or TAS-102 in patients with CRC that has spread to other areas of body
Optimal adjuvant Active,

therapy strategy not

Recruitin

g

Standard or Active

escalation or de- Recruitin

escalation

$\mathrm{g}$

Adjuvant

chemotherapy

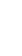

Regorafenib or Active TAS-102 or both Recruitin $\mathrm{g}$ 


\begin{tabular}{|c|c|c|c|c|c|}
\hline $\begin{array}{l}\text { NTC03688906 } \\
\text { (Freenome, Inc.) }\end{array}$ & NA & $\begin{array}{l}\text { Al-EMERGE: development } \\
\text { and validation of a multi- } \\
\text { analyte, blood-based } \\
\text { colorectal cancer } \\
\text { screening test }\end{array}$ & $\begin{array}{l}\text { Cohort A: patients who have been recently } \\
\text { diagnosed with CRC or advanced adenoma; } \\
\text { cohort B: subjects with an age of 50-84 } \\
\text { undergoing routine screening colonoscopies as } \\
\text { a part of their regular medical check-ups; } \\
\text { cohort C: patients } 18 \text { years or older who have } \\
\text { been recently diagnosed with CRC or advanced } \\
\text { adenoma } \\
\text { Main objective: to develop and validate a } \\
\text { blood-based assay for the early detection of } \\
\text { colorectal cancer }\end{array}$ & None & $\begin{array}{l}\text { Active } \\
\text { Recruitin } \\
\mathrm{g}\end{array}$ \\
\hline $\begin{array}{l}\text { NTC03637686 } \\
\text { (University } \\
\text { Aarhus) }\end{array}$ & NA & $\begin{array}{l}\text { Circulating tumor DNA } \\
\text { analysis to } \\
\text { Optimize treatment for } \\
\text { patients with } \\
\text { Colorectal cancer } \\
\text { (IMPROVE) }\end{array}$ & $\begin{array}{l}\text { All patients with stage I-III colorectal cancer, } \\
\text { scheduled for curative intended resectional } \\
\text { surgery } \\
\text { Main objective: to identify patients with a high } \\
\text { risk of recurrence with ctDNA profiling } \\
\text { performed immediately after treatment for } \\
\text { CRC }\end{array}$ & None & $\begin{array}{l}\text { Active } \\
\text { Recruitin } \\
\mathrm{g}\end{array}$ \\
\hline $\begin{array}{l}\text { NCT04264702 } \\
\text { (Natera, Inc.) }\end{array}$ & NA & $\begin{array}{l}\text { BESPOKE study of ctDNA } \\
\text { guided } \\
\text { therapy in colorectal } \\
\text { cancer }\end{array}$ & $\begin{array}{l}\text { Patients who have undergone surgery for stage } \\
\text { II or III of CRC and who have residual formalin- } \\
\text { fixed paraffin-embedded tissue available } \\
\text { Main objectives: to examine the impact of } \\
\text { Signatera TM on the decisions about adjuvant } \\
\text { treatment; to determine the rate of recurrence } \\
\text { of patients diagnosed with CRC while } \\
\text { asymptomatic using SIGNATERA TM }\end{array}$ & $\begin{array}{l}\text { Modification of } \\
\text { the adjuvant } \\
\text { treatment } \\
\text { regimen } \\
\text { according to the } \\
\text { results of the } \\
\text { post-surgical } \\
\text { SIGNATERA TM } \\
\text { ctDNA test }\end{array}$ & $\begin{array}{l}\text { Active } \\
\text { Recruitin } \\
\mathrm{g}\end{array}$ \\
\hline
\end{tabular}


The studies concerning dual HER2 targeting currently under progress provide evidence in support of benefit for HER-amplified CRCs, although this benefit appears to be limited to the wild-type RAS population [95]. A recent case report suggested possible clinical benefit in these patients with the use of trastuzumab emtansine (T-DM1) [95]. The application of ctDNA assay has been providing consistent assistance in defining the treatment in these patients [95].

Recently, a study proposed the use of ctDNA assay to detect APC, KRAS, BRAF, and CTNNB1 mutations as a population primary screening approach. In the preliminary evaluation, ctDNA assay was performed for 52 subjects who had tested positive in the Fetal Immunochemical Test, a test used as a primary screener in the screening programs for CRC, and a sensitivity of $53.8 \%$ and specificity of $92.3 \%$ was observed in the subjects with advanced adenomas [96].

\section{Translation of ctDNA Studies in Clinical Trials}

Recent studies have demonstrated the potential of ctDNA assay in guiding clinical decisions and providing direct support to cancer therapy. In this context, particularly interesting was the TARGET (Tumor characterization to Guide Experimental Targeted therapy) study, which was designed to directly evaluate the feasibility of using ctDNA, in comparison to using the standard tissue-testing, to identify the clinically actionable mutations in patients with a wide range of advanced-stage cancers [97]. In the TARGET study, mutational profiles of ctDNA were assessed using NGS, and the results for the first 100 patients were recently reported, demonstrating a good agreement with the matched tumors. When a variant allele frequency threshold of $2.5 \%$ was applied, actionable mutations were detected in $41 \%$ of the patients, among which 11 patients received matched therapies [97].

Numerous studies have supported the clinical utility of ctDNA analysis in predicting and monitoring the response of several solid tumors to specific therapies.

\section{Lung cancer}

The therapy used for non-small cell lung cancer (NSCLC) was modified drastically with the discovery of several drug-actionable genetic alterations in NSCLC patients, which led to the discovery of several biomarkers in these patients that agreed with specific treatments, including the EGFR point mutations and other alterations, ALK fusions, BRAF ${ }^{V 600 E}$ mutation, ROS1 fusions, RET fusions, MET amplification, MET exon 14 skipping variants, NTRK rearrangements, and HER2 mutations [98].

An initial study conducted within the TRACERx study provided evidence in support of the suitability of ctDNA analysis in detecting the most recurrent mutations observed in NSCLC as well as in predicting chemotherapy resistance and disease recurrence [99]. A more recent report from TRACERx study supported the view that ctDNA may serve as a biomarker for the detection of postsurgery MRD and for determining the clonality of relapsing disease [100]. In this context, Abbosh and coworkers conducted a study with 78 NSCLC patients, in which patient-specific anchoredmultiplex polymerase PCR enrichment panels were developed for analysis in accordance with the sequencing data on tumor-tissue biopsy obtained at the moment of surgery. It was reported that this strategy provided considerable improvement in MRD detection through ctDNA analysis, exhibiting a sensitivity of $89 \%$ at a VAF of $0.008 \%$ and a specificity of $100 \%$ [100]. Positive ctDNA detection was reported in 37 out of the 45 patients who experienced a relapse of their primary NSCLC; for these 37 patients, ctDNA positivity predicted the relapse approximately five months 
ahead of the clinical relapse. The 23 patients who remained relapse-free during the median followup of approximately three years were all ctDNA-negative [100].

Jiang et al. conducted a study based on ctDNA analysis with a cohort of NSCLC patients spanning stage I to stage IV using AVENIO ctDNA Surveillance kit (Roche Co., USA), which is a liquid biopsy platform that utilizes NGS in disease surveillance and/or monitoring of lung and colorectal cancers, and the gene panel used in this platform spans the regions of 197 genes [101]. In order to perform this analysis, a deep sequencing (CAPP-Seq) was used, and the mutations observed in the ctDNA were compared to those identified in the matched tumor-tissue samples. The mutational concordance was observed to clearly increase with tumor stage: $12 \%$ in stage I tumors, $58 \%$ in stage $\mathrm{II}, 56 \%$ in stage III, and $74 \%$ in stage IV tumors [101]. The amount of cfDNA available for ctDNA analysis and a VAF not $<0.5 \%$ was the fundamental parameter to achieve a good concordance between the results of ctDNA analysis and tissue-biopsy analysis [101].

Approximately $30 \%-35 \%$ of NSCLC patients exhibit EGFR alterations. Majority of the patients harboring an EGFR-TKI (a tyrosine kinase inhibitor) sensitizing mutations respond to treatments with first-generation or second-generation EGFR-TKIs. Osimertinib was reported to improve survival in these patients and has now been approved as a first-line treatment option or for the patients with T790M-positive NSCLC after disease progression on first-line EGFR-TKIs [102].

The EGFR mutational status has been continually explored in NSCLC EGFR-mutant patients. In 2016, the cobas EGFR mutation test 2 (Roche Molecular Systems), which is capable of detecting 42 different EGFR mutations in exons 18-21 in tissue-derived as well as plasma-derived DNA, received the FDA approval. The study of the use of this test in the NSCLC patients enrolled in the ENSURE trial concluded that ctDNA assay could be recommended as a suitable alternative to tissue biopsy analysis for the assessment of EGFR mutational status [107, 108]. Importantly, the Liquid Long-OCohort trial involving the evaluation of the efficacy of Osimertinib through ctDNA analysis of NSCLC patients using the Cobas EGFR mutation test 2 recommended ctDNA analysis as a feasible alternative to tumor biopsies for the screening of acquired $E G F R^{T 790 M}$ resistance mutation [105]. The same conclusion was reached in the FLAURA study (NCT 02296125), through the retrospective analysis of 217 NSCLC patients, with the result of $97 \%$ concordance in the detection of EGFR mutational status between ctDNA analysis and tissue biopsy analysis [105].

A proportion of NSCLC patients with EGFR ${ }^{T 790 M}$ mutations develop resistance to Osimertinib, and these patients could be treated with afatinib. The mutation profile of such patients in ctDNA was analyzed recently using CAPP-sequencing. The $E G F R^{C 7975}$ mutation was observed in a few of these patients prior to commencing the afatinib treatment, while the other patients exhibited the development of this mutation following the treatment with this drug [106].

Certain clinical trials currently under progress, such as the MELROSE phase II trial, have included ctDNA analysis as a tool for evaluating the genetic tumor profile at the time of disease progression in the NSCLC patients undergoing treatment with Osimertinib [107], while other studies have supported the capacity of ctDNA assay to detect other genetic alterations observed in NSCLC, such as $A L K$ or ROS1 translocations [108].

Interestingly, certain recent studies have demonstrated the validity and utility of Guardant 360 test in planning therapeutic choices in NSCLC patients. Guardant 360 test was the first clinicallyvalidated test that allowed the multiplex molecular analysis of genetic alterations in eight different genes- EGFR, ALK, BRAF, RET, ROS1, MET, HER2, and NTRK. In the NILE study, the Guardant 360 assay demonstrated $>90 \%$ concordance with tissue biopsy DNA assay [109]. 
A percentage of NSCLC patients are sensitive to immunotherapy based on the administration of immune check inhibitors, particularly the programmed death 1 (PD-1) and programmed deathligand 1 (PD-L1) inhibitors. High PD-L1 expression and high tumor mutational burden represent the two major determinants of the patient's response. In this context, a technology to measure tumor burden in the plasma DNA was developed, and it was demonstrated that the patients with high tumor burden obtained benefit in terms of PFS from the treatment with an anti-PD-L1 inhibitor [110]. Similarly, Wang et al. demonstrated that a high tumor burden was associated with better PFS and objective response rates [111]. Reduction in the levels of ctDNA is predictive of response in the NSCLC patients undergoing immune checkpoint blockade $[112,113]$. It is reported that ctDNA analysis could be utilized for surveillance of patients obtaining long-term benefit from PD-L1 blockade; the ctDNA-negative patients remained progression-free in a large majority of cases, while the ctDNA-positive patients exhibited disease-progression [114].

Interestingly, a recent study reported plasma-based comprehensive genomic sequencing of 8,388 consecutively-tested advanced NSCLC using the NGS platform Guardant 360 [115]. The ctDNA analysis revealed somatic alterations in $86 \%$ of these cases, with the identification of therapeutically targetable and resistant mutations [119]. On the basis of these data, the use of comprehensive ctDNA testing was proposed for the NSCLC patients who are incompletely tested at the time of diagnosis and for those who are in progression on targeted therapies [115].

Early detection of lung cancers through ctDNA analysis is quite difficult owing to the low levels of ctDNA present in the plasma in stage I-III lung cancers. In order to resolve this issue, a novel approach for non-invasive NSCLC screening, which integrates improved molecular techniques with machine learning, was reported for the detection of NSCLC-derived cfDNA in blood samples. This approach was based on personalized cancer profiling using deep sequencing (CAPP-Seq) [15, 16]. The results of the application of this approach indicated the following: (i) ctDNA is present, although in minute levels, prior to treatment in most of the patients, and its presence is clearly highly prognostic; (ii) majority of the mutations in the cfDNA of these patients, as well as in the agematched controls, are related to clonal hematopoiesis, are non-recurrent, and mostly involve the genes DNMT3A, TET2, TP53, PPM1D, and SF3B1; (iii) in comparison to tumor-related mutations, clonal hematopoiesis mutations occur in longer cfDNA fragments and lack the mutational signatures that are associated with tobacco smoking; (iv) the integration of these characteristics, together with other molecular features, enabled the development of a machine-learning method, proposed as "lung cancer likelihood in plasma" (Lung-CLiP), which is capable of clearly discriminating early-stage lung cancers from the matched-controls [116].

\section{Melanoma}

Molecular studies have revolutionized melanoma therapy, particularly with the discovery of several molecular biomarkers that are expressed selectively in certain subgroups of patients and are suitable for target therapy [117]. On the basis of the pattern of the most recurrent gene mutations, four subtypes were identified: mutant $B R A F$, mutant RAS, mutant NF1, and triple-wildtype (kit mutations, focal amplifications, and complex structural rearrangements are the typical characteristics of the triple-WT subtype) [118].

Several studies support the view that detection of ctDNA in metastatic melanoma patients is a sensitive tool for monitoring and prediction for the early assessment of disease progression and therapeutic response. Elevated ctDNA levels at baseline represent an independent prognostic factor 
of disease progression. A study reported a correlation between alterations in the ctDNA levels during therapy and the tumor response, with an increase in the levels being predictive of disease progression and a decrease being predictive of treatment response. Detection of NRAS ${ }^{Q 61}$ ctDNA in the baseline samples of patients with $B R A F^{V 600 E}$ mutation who were treated with MAPK inhibitors was reported to be associated with shorter PFS [119]. Another recent study corroborated this finding by demonstrating that increasing levels of ctDNA during melanoma treatment with targeted therapy or immunotherapy could predict disease progression prior to the progression becoming apparent in radiological imaging [120].

Braune and coworkers evaluated ctDNA levels for detecting tumor burden in BRAF-mutant and NRAS-mutant stage III/IV melanoma patients, and also investigated whether early changes in the ctDNA levels could predict response to treatment. The authors reported that $46 \%$ of stage IV and $63 \%$ of stage III melanoma cases were positive for ctDNA [125]. Importantly, ctDNA detection demonstrated superior sensitivity to LDH and S100 in detecting active disease in stage III and IV melanomas [121]. Dynamic changes in ctDNA occurred within 30 days after the initiation of treatment and preceded the clinical response or progression [121].

Lee and coworkers demonstrated that pre-operative ctDNA is capable of predicting survival in high-risk stage III cutaneous melanoma patients [122]. These findings support the potential clinical utility of ctDNA as a biomarker for determining the prognosis and stratifying stage III melanomas.

It is noteworthy that ctDNA analysis provides an accurate measure of extracranial metastatic disease and not of intracranial metastatic disease in melanoma patients [123]. This finding strongly limits the application of ctDNA analysis as an exclusive test during the surveillance and therapeutic monitoring of patients with melanomas [123].

\section{Breast Cancer}

Breast cancer $(B C)$ is the most common type of cancer in women. At the molecular level, $B C$ is a heterogeneous disease characterized by high genomic instability, as evidenced by the presence of somatic gene mutations, copy number alterations, and chromosomal structural rearrangements. On the basis of its molecular characteristics, breast cancer is divided into different subtypes according to the presence of hormone receptors [estrogen receptor $(E S R)$ and progesterone receptor $(P R)]$ and of epidermal growth factor receptor 2 (HER2) and/or BRCA mutations [124]. Approximately $80 \%$ of the BCs express hormone receptors and several of the patients with such $B C$ are treated with surgery and endocrine therapy, with approximately one-third of these patients exhibiting a scarce response to therapy due to either innate, or more frequently, acquired drug resistance. Various mechanisms are responsible for the development of drug resistance, the majority represented by the acquisition of mutations at the level of ESR1 gene and the acquisition of several alterations in the genes involved in MAPK pathway (such as NF1 loss, HER2 mutations, EGFR mutations, and KRAS mutations) [125].

In a study, ESR1 mutations in $\mathrm{H}^{+} \mathrm{BC}$ patients who were treated with an aromatase inhibitor were detected using droplet digital PCR analysis. The results revealed that $28.8 \%$ of the patients had ESR 1 mutation D538G, 21\% of the patients had ESR1 mutation Y537S, and the presence of these mutations was associated with shorter OS [126]. Interestingly, Lupini and coworkers reported significant improvement in the sensitivity of an assay for monitoring ESR1 mutations in cfDNA with the use of an enhanced-ice-COLD-PCR, a methodology that enabled the detection of ESR1 mutations even when these mutations constituted only $0.01 \%$ of the total ESR1 allelic fraction [127]. With the 
use of this methodology, the authors could detect ESR1 mutations at codons 536-538 in patients with metastatic ER-positive BC [127].

Other studies were focused on assessing the capacity of ctDNA assays to detect and monitor PI3KCA mutations. PIK3CA mutations occur in approximately $40 \%$ of the BCs with hormone receptors. Recent studies have demonstrated that breast cancer patients could be treated with PI3K inhibitors, such as alpelisib, achieving significant benefit in their PFS [128]. Various studies have demonstrated that PIK3CA mutations could be detected with an efficiency of $80 \%$ through ctDNA analysis, with the considerably high concordance with tissue analysis. In addition, the presence of PIK3CA mutations in ctDNA was associated with better response to PIK3 inhibitors [129, 130].

In 2019, the FDA approved the clinical use of the PI3K inhibitor alpelisib in post-menopausal women with advanced-stage or metastatic BC, concomitantly with therascreen PIK3CA RGQ PCR kit (Qiagen), which is capable of detecting 11 different mutations at the level of PIK3CA gene in tumor tissue as well as in plasmatic ctDNA [128].

Currently, CDK4/6 inhibition with endocrine therapy is a standard of care in patients with advanced ER-positive BC. A phase III randomized clinical study, PALOMA-3, investigated the therapeutic effect of Palbociclib (a CDK4/6 inhibitor) in combination with fulvestrant compared to placebo plus fulvestrant. This study performed an extensive investigation at the level of ctDNA, using two different techniques of ctDNA analysis, namely, BEAMing and Droplet Digital PCR, for the detection of PI3KCA and ESR1 mutational status, which demonstrated sufficient reproducibility for clinical testing [131]. Another study utilized ctDNA analysis to explore the mechanisms of resistance. In this study, RB1 mutations emerged only in the Palbociclib plus fulvestrant arm, while novel driver mutations emerged in both PIK3CA and ESR1 after treatment arms [132]. Another parallel study demonstrated that in these patients, relative changes in the PIK3CA levels after 15 days of treatment were a strong predictor of PFS in Palbociclib and fulvestrant treatment groups [133].

The ctDNA technology has also been used for the screening of the mutational spectrum in advanced/metastatic BC. In this context, an initial study conducted by Dawson et al. reported that ctDNA was positive in $97 \%$ of the women with metastatic BC, indicating that in these patients, ctDNA levels correlated with tumor burden and provided the earliest measure of treatment response [134]. In particular, the use of deep sequencing enabled the detection of a large spectrum of mutations in the ctDNA samples of $\mathrm{H}$-positive metastatic BC patients. Therefore, the assay was suitable both as a screening procedure and as a monitoring tool through longitudinal analysis during the treatment [135]. A study demonstrated that the Oncomine breast cfDNA assay was suitable for the detection of clinically significant mutations, such PIK3CA, TP53, and ESR1 mutations, in $\mathrm{H}$ positive metastatic BC patients [136]. Interestingly, ctDNA analysis in metastatic BC patients explored at the level of several metastatic sites in autopsy revealed that ctDNA profiling is representative of widespread disease [137]. Early dynamic changes in ctDNA were explored in phase I/II BEECH trial, which involved ER-positive BC patients with advanced disease who were being treated either with paclitaxel plus placebo or with paclitaxel plus AKT inhibitor capivasertib. The study reported a PFS of 11.1 months in patients with suppressed ctDNA levels following treatment and a PFS of 6.4 months in patients with high ctDNA levels [138]. These data indicated that early ontreatment ctDNA dynamics might be a surrogate for PFS [138].

A study was conducted with 101 women having early-stage BC who received either neo-adjuvant chemotherapy followed by surgery or surgery prior to adjuvant chemotherapy, in order to assess the clinical utility of ctDNA evaluation during treatment. Initially, primary tumors were sequenced to identify the somatic mutations, and personalized tumor-specific and patient-specific digital PCR 
assays were employed for the detection of mutations in sequential ctDNA samples obtained after treatments and during follow-up [143]. Detection of ctDNA during follow-up was reported to be associated with relapse, and the median lead time of ctDNA detection compared to clinical relapse was 10.7 months. Moreover, distant extracranial metastases could be detected using ctDNA, while the detection of brain-only metastases using ctDNA was further rare [139]. Recently, researchers used ctDNA analysis for the detection of MRD after neoadjuvant therapy in breast cancer, a condition that requires high detection sensitivity, to define mutations at a VAF of $0.001 \%$ [130]. In order to achieve this, McDonald and coworkers developed targeted digital sequencing for a multiplexed analysis of cancer-specific mutations [140]. This assay was evaluated in 30 women with BC stage I-III who were undergoing neo-adjuvant treatment, and it was reported that after the neoadjuvant therapy, ctDNA concentrations were lower in the patients achieving complete pathological responses. Furthermore, a decrease in ctDNA levels was detected during neo-adjuvant therapy [140]. This strategy was also adopted in another recent study with the specific aim of utilizing the ctDNA assay for predicting complete pathological response in 84 high-risk early BC patients treated with the neoadjuvant I-SPY2 TRIAL [141]. The results of this interesting study revealed that lack of ctDNA clearance was a significant predictor of poor response and metastatic recurrence, while clearance was associated with improved survival independent of the pathological response [141]. These studies support the view that personalized monitoring of ctDNA during neo-adjuvant chemotherapy may assist in real-time assessment of treatment response, and together with pathological response, may contribute to predicting the patient's survival.

Coombes et al. investigated the potential clinical utility of ctDNA as a biomarker for disease surveillance of patients with BC [142]. In this investigation, 49 primary patients with breast cancer were recruited after surgery and adjuvant therapy, and the plasma samples were collected every six months for up to four years. The collected samples were subjected to ctDNA analysis using personalized assays targeting 16 gene variants selected from the primary tumor whole-exome data. The results revealed that out of 49 patients, 18 patients relapsed, among which 16 patients were detected in the ctDNA assay. In these 16 patients, metastatic relapse was predicted with a lead time of up to two years [142].

\section{Prostate Cancer}

Prostate cancer is the most common cancer among men and second among the leading causes of cancer death in western nations [143]. Clinically, prostate cancer is a heterogeneous disease, with certain patients exhibiting an aggressive disease with a tendency to progression, while others demonstrate an indolent course [143]. Three stages of tumor development are reported for prostate cancer: intraepithelial neoplasia, androgen-dependent adenocarcinoma, and androgenindependent or castration-resistant adenocarcinoma [143].

A limited number of studies have assessed the diagnostic and prognostic impact of ctDNA evaluation in localized early prostate cancer. Among these, a key study conducted by Schwarzenbach and coworkers reported the detection of cfDNA in 45\% of the patients with localized prostate cancer and demonstrated a positive correlation between the ctDNA levels and the tumor stage or Gleason score [144]. Chun et al. evaluated the ctDNA levels in 161 men, 142 of whom had clinically localized prostate cancer, while 19 had benign prostatic hyperplasia (BPH). The prebiopsy cfDNA levels in the BPH patients were significantly different from the levels in localized prostate cancer patients [145]. Another study confirmed the presence of higher levels of cfDNA in the plasma 
of patients with localized prostate cancer compared to patients with BPH and healthy subjects [146]. However, it is also reported that ctDNA is unable to distinguish BPH patients from normal individuals [146]. This is because the levels of ctDNA observed in the BPH patients are extremely low, as reported in certain recent studies. Therefore, Hennigan and coworkers applied ultra-low-pass whole-genome sequencing to profile the cell-free DNA isolated from 112 patients with localized prostate cancer and concluded that the allele-specific alterations in ctDNA were below the threshold level required for detection [147].

Most of the studies utilizing cfDNA have been performed in metastatic prostate cancer patients. Wyatt and coworkers conducted a study comparing cfDNA analysis with tissue biopsy in 45 patients with metastatic prostate cancer, in which they analyzed 72 clinically-relevant driver genes [148]. Importantly, all the somatic mutations observed in matched solid biopsies were confirmed in liquid biopsies as well [148]. The study concluded that ctDNA assay could certainly be used for disease stratification in metastatic prostate cancer patients [148].

Furthermore, Wyatt et al. explored the clinical potential of ctDNA in 65 patients with metastatic prostate cancer undergoing treatment with enzalutamide, and reported that $38 \%$ of these patients responded to treatment [149]. The patients were examined for mutations at the level of 19 prostate cancer-associated genes, and the mutational profiles obtained in ctDNA analysis and tissue biopsy analysis were similar. In addition, the patients with AR copy-number gains and/or amplifications, multiple $A R$ mutations, RB1 loss, MET gain, and MYC gain presented a higher probability of enzalutamide resistance [153]. Furthermore, in this study, as well as in a study conducted by Azad et al. [150], $A R^{F 877 L}$ mutation was reported as the underlying mechanism for resistance to enzalutamide.

Conteduca et al. used the digital droplet PCR assay to study the $A R$ copy number and mutations in the sequential plasma DNA samples from two cohorts of metastatic prostate cancer patients treated with enzalutamide or abiraterone. In both the cohorts, the presence of $A R$ amplification was reported to be associated with poorer OS and PFS [151].

Annala and coworkers conducted an interesting study that involved randomization of 202 patients with metastatic prostatic cancer to abiraterone or enzalutamide along with whole-exome and deep targeted sequencing of 72 genes of plasma DNA prior to the commencement of therapy [152]. It was observed that in these patients, ctDNA fraction (\% of ctDNA with respect to total cfDNA) was associated with tumor burden and clinical outcomes [152]. The analysis of the mutational profile of ctDNA enabled defining several genetic alterations associated with poor outcomes: defects in BRCA2 and ATM were observed to be strongly associated with poor outcomes; TP53 mutations were associated with rapid resistance; and certain $A R$ alterations, such as $A R$ structural rearrangements truncating the ligand binding domain, were associated with primary resistance [152].

Choudhury and coworkers demonstrated that the fraction of circulating DNA of tumor origin is a biomarker for castration-resistant prostate cancers, as it is associated with a number of bone and visceral metastases and also with the other parameters of disease extension/progression. However, it was observed that the ctDNA levels did not correlate with the PSA levels [153]. In addition, effective treatments in these patients were associated with a decline in ctDNA levels [153].

It is noteworthy that the analysis of whole-genome sequencing data from cfDNA has contributed to the identification of frequently recurrent tandem duplications that involve an upstream enhancer of $A R$ that is present in $70 \%-87 \%$ of these patients. In a few of these patients, duplication of the $A R$ enhancer occurred in association with CDK 12 inactivation [154]. 
Goodal et al. provided data in support of the clinical utility of cfDNA analysis in monitoring the metastatic prostate cancer patients undergoing treatment with the PARP inhibitor Olaparib in the phase II trial TOPARP-A, and demonstrated its clinical benefit in patients with homologous recombination DNA repair defects [155]. All tumor-tissue somatic DNA-repair mutations were reported to decrease in the responding patients [155]. These findings are in support of the clinical utility of liquid biopsies in monitoring the response to PARP inhibitors in metastatic prostate cancer patients [155].

Quite recently, Kohli et al. reported the results of a longitudinal study involving plasma cfDNA/ctDNA evaluation performed prior to, during, and after androgen deprivation therapy, in various groups of prostate cancer patients ranging from untreated metastatic hormone-sensitive patients to the metastatic castration-resistant tumor bearing ones. [156]. The study involved the use of next-generation sequencing on ctDNA, and the results demonstrated that: the cfDNA levels in progressive hormone-sensitive patients were different from those in the hormone-resistant patients; in hormone-sensitive patients, higher ctDNA fraction was predictive of a shorter time for progression to androgen independency; cfDNA and ctDNA values, together with the volume of metastatic disease were highly predictive of survival; and ctDNA mutations were more frequent among the androgen-independent patients compared to the androgen-sensitive ones, with the TP53 mutations, RB1 loss, and AR gene amplifications correlating with poorer survival [156]. These findings further support the consistent clinical utility of ctDNA evaluation in refining the prognosis in metastatic prostate cancer patients.

A quite recent study demonstrated the potential use of ctDNA assay in recognizing the transformation of advanced prostate cancer into castration-resistant neuro-endocrine prostate cancer. In this study, Beltran and coworkers identified that a targeted set combining genomic (TP53, $R B 1, C Y L D$, and $A R$ ) and epigenomic (hypo- and hyper-methylation of 20 differential sites) alterations when applied to ctDNA was capable of identifying the patients undergoing neuroendocrine transformation [157].

\section{Conclusions}

An increasing number of studies have reported several potential applications of ctDNA assays performed on the plasma samples obtained at various time-points during disease evolution, thereby providing elements for diagnosis and the identification of response/resistance to therapy, recurrence, presence of MRD, and potential therapeutic targets. To date, two ctDNA assays have received approval from the FDA: one for the identification of specific EGFR mutations in metastatic and locally-advanced NSCLC; and the other for the evaluation of PIK3CA mutations in $\mathrm{H}^{+} / \mathrm{HER} 2$ advanced breast cancer in progression or after endocrine therapy.

In spite of the consistent progress in the technology of ctDNA analysis, this approach presents several limitations, most of which are related to the scarcity of ctDNA in several tumors and the absolute requirement of assessing the tumoral origin of mutations detected in the cfDNA.

In this context, a recent study by Razavi et al. proposed a novel technology, which utilized a strategy to bypass these limitations. The authors used ultra-deep sequencing of paired plasma cfDNA and white blood cells, thereby enabling the identification of tumor-derived somatic mutations with an elevated accuracy through the elimination of all variants apparently related to clonal hematopoiesis [158]. In this study, 124 patients with metastatic cancer (breast, prostate, and lung) and 47 control subjects were analyzed at the level of ctDNA, white blood cell DNA, and tissue 
biopsies [158]. Almost all the mutations absent in the WBCs detected in normal controls occurred at a variation allelic frequency of $<1 \%$, while approximately $50 \%-55 \%$ of the mutations observed in metastatic tumors were detected at a VAF of $<1 \%$. In addition, somatic mutations with high VAF observed in the ctDNA of cancer patients were reported to be tumor-matched, thereby indicating their tumor origin [158]. Interestingly, this approach enabled the detection of variants of unknown origin, which were not detected either in tumor biopsies or in the WBCs. These variants might have variegated origins, although they might also englobe a set of alterations, a few of which may reflect tumor evolution and heterogeneity, undetectable in tissue biopsies [158]. These observations are important as they indicate the complexity of detecting the mutational repertoire of plasma ctDNA and the necessity of considering the frequent occurrence of clonal hematopoiesis [158].

The fundamental opportunity offered by ctDNA analysis is represented by its capacity to potentially identify multiple concurrent heterogeneous resistance mechanisms occurring in individual patients that might go undetected in single-lesion tumor biopsies. Indeed, since cfDNA may be shed into the blood from multiple tumor lesions in individual patients, this approach may provide an anatomically unbiased evaluation of both primary and metastatic sites, thereby providing information on tumor heterogeneity. In this context, Strickler et al. performed a remarkable NGS analysis on the cfDNA obtained from 1,397 colorectal cancer patients, with the following findings: (i) the frequencies of genomic alterations detected in cfDNA were largely comparable to those observed in three independent tissue-based colorectal sequencing data banks; (ii) the analysis of VAF of mutated genes revealed that certain genes, such as KRAS, FBXW7, APC, $S M A D 4, B R A F$, and TP53 exhibited a clonal mutational pattern, while certain other mutated genes, such as EGFR, exhibited a subclonal pattern; (iii) a high percentage ( $>50 \%$ ) of patients with EGFR mutations exhibited mutations at the level of the extracellular domain and high tumor heterogeneity, with multiple distinct resistance alterations [159].

The third finding was corroborated by a recent study that compared cfDNA analysis with the standard single-lesion tumor biopsies in a cohort of 42 patients with molecularly-defined gastrointestinal cancers and reported the development of acquired resistance to targeted therapy [160]. The direct comparison of post-progression ctDNA with tumor biopsy revealed that cfDNA analysis identified the clinically relevant resistance alterations and multiple resistance mechanisms more frequently, detecting even the genetic alterations mediating the resistance, which could not be detected using matched single biopsy, in $78 \%$ of the cases [160].

A combination of ctDNA detection with the current diagnostic imaging analysis may provide considerable improvement in the early identification of patients with localized tumors who are at elevated risk of disease evolution. In this context, particularly interesting was the recent study conducted by Azad et al., which was based on deep sequencing analysis of plasma DNA isolated from 45 patients prior to and after the chemo-radiotherapy for esophageal cancer [161]. The results of this study revealed that: (i) ctDNA detection after chemo-radiotherapy was associated with tumor progression; (ii) a higher percentage of patients with tumor progression presented detection of novel mutations in the ctDNA compared to the patients without progression; (iii) ctDNA detection after chemo-radiotherapy preceded the clinical relapse by a median lead of 2.8 months; (iv) the combination of ctDNA evaluation and metabolic imaging analysis predicted tumor progression in $100 \%$ of the patients receiving chemo-radiotherapy without surgery [161].

The future of ctDNA studies concerns the possibility of application of this technology for early cancer detection. In this context, particularly interesting were the results of a study recently reported by Lennon et al. which demonstrated the feasibility of a multi-modal blood testing 
combined with PET scans for the screening of cancer and guide intervention [162]. The authors conducted an exploratory prospective interventional study, referred to as DETECT-A (Detecting cancers Earlier Through Elective mutation-based blood Collection and Testing), to evaluate a version of a multi-analyte blood test incorporating the analysis of $\operatorname{cFDNA}$, and tumor-related protein biomarkers similar to the CANCER SEEK test reported by Cohen et al. [18]. The study investigated 10,006 women who were not previously known to have cancer. Positive blood tests were confirmed through double analysis (a screening analysis followed by a confirmation analysis) and a diagnostic PET-CT radiographic analysis, which localized cancer [162]. A total of 26 cancers were detected using blood testing, while 15 were detected in PET-CT imaging and were removed surgically [166]. This study indicated the potential utility of multi-cancer blood testing in combination with PET-CT in routine clinical care [162].

The Circulating Cell-free Genome Atlas (CCGA) study was designed to evaluate whether a combination of genome-wide cfDNA sequencing and machine learning could detect and localize a large number of cancer types with a high specificity that could be considered sufficient for a general population-based cancer screening program. Recently, the results for 2,482 cancer patients and 4207 non-cancer individuals on the plasma cfDNA analysis performed using bi-sulfate sequencing targeting a panel of $>100,000$ informative methylation regions were reported [163]. The cfDNA analysis provided informative methylation patterns in $>50$ cancer types spanning different tumor stages. It was reported that the assay had the potential for the early detection of various cancers, and further evaluation of this assay in prospective population-level studies is warranted.

The analysis of the most recent clinical studies demonstrated that ctDNA analysis is being increasingly used for appropriate therapy selection. In the future, it is expected that carefully designed clinical trials involving ctDNA analysis would contribute to accelerating drug development, better understanding tumor evolution/progression, increasing the number of cancer patients who would receive the appropriate targeted therapy, better monitoring treatment efficacy, and globally improving the therapeutic efficacy of precision medicine.

\section{Author Contributions}

All the authors have equally contributed to this manuscript, through search of bibliography, reading and interpretation of manuscripts and preparation of the present manuscript. Particularly, GC contributed to the preparation of Tables, EP to the searching of the literature and preparation of bibliography and UT to the supervision and final preparation of the manuscript.

\section{Competing Interests}

The authors have declared that no competing interests exist.

\section{References}

1. Ashley EA. Towards precision medicine. Nat Rev Genet. 2016; 17: 507-522.

2. Kumar-Sinha C, Chinnaiyan AM. Precision oncology in the age of integrative genomics. Nat Biotechnol. 2018; 36: 46-60.

3. Moscow JA, Fojo T, Schilsky RL. The evidence framework for precision cancer medicine. Nat Rev Clin Oncol. 2018; 15: 183-192. 
4. Teutsch SM, Bradley LA, Palomaki GE, Haddow JE, Piper M, Calonge N, et al. The evalution of genomic applications in practice and prevention (EGAPP) initiative: Methods of the EGAPP working group. Genet Med. 2009; 11: 3-14.

5. Pantel $\mathrm{K}$, Alix-Panabières $\mathrm{C}$. Liquid biopsy and minimal residual disease - latest advances and implications for cure. Nat Rev Clin Oncol. 2019; 16: 409-424.

6. Pantel K, Alix-Panabières $\mathrm{C}$. Circulating tumor cells in cancer patients: Challenges and perspectives. Trends Mol Med. 2010; 16: 398-406.

7. Dawson SJ, Tsui DW, Murtaza M, Biggs H, Rueda OM, Chin SF, et al. Analysis of circulating tumor DNA to monitor metastatic breast cancer. N Engl J Med. 2013; 368: 1199-1209.

8. Thierry AR, Messaoudi SE, Gahan PB, Anker P, Stroun M. Origins, structures, and functions of circulating DNA in oncology. Cancer Metastasis Rev. 2016; 35: 347-376.

9. Stroun M, Lyautey J, Lederrey C, Olson-Sand A, Anker P. About the possible origin and mechanism of circulating DNA apoptosis and active DNA release. Clin Chim Acta. 2001; 313: 139-142.

10. Toth K, Patai AV, Kalmar A, Bartak BK, Nagy ZB, Galamb O, et al. Circadian rhythm of methylated septin 9, cell-free DNA amount and tumor markers in colorectal cancer patients. Pathol Oncol Res. 2017; 23: 699-706.

11. Meddeb R, Amir Dache ZA, Thezenas S, Otandault A, Tanos R, Pastor B, et al. Quantifying circulating cell-free DNA in humans. Scient Rep. 2019; 9: 5220.

12. Liu J, Chen X, Wang J, Zhou S, Wang CL, Ye MZ, et al. Biological background of the genomic variations of cf-DNA in healthy individuals. Ann Oncol. 2019; 40: 464-470.

13. Wan JC, Massie C, Garcia-Corbacho J, Mouliere F, Brenton JD, Caldas C, et al. Liquid biopsies come of age: Towards implementation of circulating tumor DNA. Nat Rev Cancer. 2017; 17: 223-233.

14. Bettegowda C, Saussen M, Leary RJ, Kinde I, Wang Y, Agrawal N, et al. Detection of circulating tumor DNA in early- and late-stage human malignancies. Sci Trasl Med. 2014; 6: 224 ra24.

15. Newman AM, Bratman SV, To J, Wynne JF, Eclov NC, Modlin LA, et al. An ultrasensitive method for quantitating circulating tumor DNA with broad patient coverage. Nat Med. 2014; 20: 552558.

16. Newman AM, Lovejoy AF, Klass DM, Curtz DM, Chabon JJ, Scherer F, et al. Integrated digital error suppression for improved detection of circulating tumor DNA. Nat Biotechnol. 2016; 34: 547-555.

17. Merker JD, Oxnard GR, Compton C, Diehn M, Hurley P, Lazar AJ, et al. Circulating tumor DNA analysis in patients with cancer: American Society of Clinical Oncology and College of American Pathologists joint review. Arch Pathol Lab Med. 2018; 142: 1242-1253.

18. Bardelli A, Pantel K. Liquid biopsies, what we do not know (yet). Cancer Cell. 2017; 31: 172-179.

19. Cohen JD, Li L, Wang Y, Thoburn C, Afsari B, Danilova L, et al. Detection and localization of surgically resectable cancers with a multi-analyte blood test. Science. 2018; 359: 926-930.

20. Mouliere F, Chandrananda D, Piskorz AM, Moore EK, Morris J, Ahlborn LB, et al. Enhanced detection of circulating tumor DNA by fragment size analysis. Sci Transl Med. 2018, 10: eeat4921.

21. Cristiano S, Leal A, Phallen J, Fiksel J, Adleff V, Bruhm DC, et al. Genome-wide cell-free DNA fragmentation in patients with cancer. Nature. 2019; 570: 385-389.

22. Coaxley M, Garcia-Murillas I, Turner NC. Molecular residual disease and adjuvant trial design in solid tumors. Clin Cancer Res. 2019; 25: 6026-6034. 
23. Diehl F, Schmidt K, Choti MA, Romans K, Godman S, Li M, et al. Circulating mutant DNA to assess tumor dynamics. Nat Med. 2008; 14: 985-990.

24. Pelosi E, Castelli G, Testa U. Pancreatic cancer: Molecular characterization, clonal evolution and cancer stem cells. Biomedicines. 2017; 5: 65.

25. Bailey P, Chang DK, Nones K, Johns AL, Patch AM, Gingras MC, et al. Genomic analyses identify molecular subtypes of pancreatic cancer. Nature. 2016; 531: 47-52.

26. Sausen M, Phallen J, Adleff V, Jones S, Leary RJ, Barrett MT, et al. Clinical implications of genomic alterations in the tumour and circulation of pancreatic cancer patients. Nature Commun. 2015; 6: 7686.

27. Cohen JD, Javed AA, Thoburn C, Wong F, Tie J, Gibbas P, et al. Combined circulating tumor DNA and protein biomarker-based liquid biopsy for the earlier detection of pancreatic cancers. Proc Natl Acad Sci USA. 2017; 114: 10202-10207.

28. Allenson K, Castillo J, San Lucas FA, Scelo G, Kim DU, Bernard V, et al. High prevalence of mutant KRAS in circulating exosome-derived DNA from early-stage pancreatic cancer patients. Annals of Oncol. 2017, 28, 741-747.

29. Kruger S, Heinemann V, Ross C, Diehl F, Nagel D, Ormanns S, et al. Repeated mut KRAS ctDNA measurements represent a novel and promising tool for early response prediction and therapy monitoring in advanced pancreatic cancer. Ann Oncol. 2018; 29: 2348-2355.

30. Kim MK, Woo SM, Park B, Yoon KA, Kim YH, Joo J, et al. Prognostic implications of multiplex detection of KRAS mutations in cell-free DNA from patients with pancreatic ductal adenocarcinoma. Clin Chem. 2018; 64: 726-734.

31. Cheng $H$, Luo G, Jin $K$, Fan Z, Huang $Q$, Gong $Y$, et al. Kras mutation correlating with circulating regulatory $T$ cells predicts the prognosis of advanced pancreatic cancer patients. Cancer Med. 2020; 9: 2153-2159.

32. Bernard V, Kim DU, San Lucas FA, Castillo J, Allenson K, Mulu FC, et al. Circulating nucleic acids are associated with outcomes of patients with pancreatic cancer. Gastroenterology. 2019; 156: 108-118.

33. Wei $T$, Zhang $Q$, Li X, Su W, Li G, Ma T, et al. Monitoring tumor burden in response to FOLFIRINOX chemotherapy via profiling circulating cell-free DNA in pancreatic cancer. Mol Cancer Ther. 2019; 18: 196-203.

34. Sugimori M, Sugimori K, Tsuchiya H, Suzuki Y, Tsuyuki S, Kaneta Y, et al. Quantitative monitoring of circulating tumor DNA in patients with advanced pancreatic cancer undergoing chemotherapy. Cancer Sci. 2020; 111: 266-278.

35. Groot VP, Mosier S, Javed AA, Teinor JA, Gemenetzis G, Ding D, et al. Circulating tumor DNA as a clinical test in resected pancreatic cancer. Clin Cancer Res. 2019; 25: 4973-4984.

36. Mohan S, Ayub M, Rothwell DG, Gulati S, Kilerci B, Hollebecque A, et al. Analysis of circulating cell-free DNA identifies KRAS copy number gain and mutation as a novel prognostic marker in pancreatic cancer. Sci Rep. 2019; 9: 11610.

37. Hendriksen DS, Madsen PH, Larsen AC, Johansen MB, Pedersen IS, Krarup H, et al. Cell-free DNA promoter hypermethylation in plasma as a predictive marker for survival of patients with pancreatic adenocarcinoma. Oncoterget. 2017; 8: 93942-93956.

38. Hendriksen DS, Madsen PH, Larsen AC, Johansen MB, Pedersen IS, Krarup H, et al. Promoter hypermethylation in plasma-derived cell-free DNA as a prognostic marker for pancreatic adenocarcinoma. Int J Cancer. 2017; 141: 2489-2497. 
39. Eissa MA, Lerner L, Abdelfatah E, Shankar N, Canner JK, Hasan NM, et al. Promoter methylation of ADAMTS1 and BCN1 as potential biomarkers for early detection of pancreatic cancer in blood. Clin Epigenetics. 2019; 11: 59.

40. Yang Z, LaRiviere MJ, Ko J, Till JE, Christensen T, Yee SS, et al. A multianalyte panel consisting of extracellular vesicle miRNAs and mRNAs, cfDNA, and CA19-9, shows utility for diagnosis and staging of pancreatic ductal adenocarcinoma. Clin Cancer Res. 2020.

41. Liu X, Liu L, Ji Y, Li C. Wei T, Yang X, et al. Enrichment of short mutant cell-free DNA fragments enhanced detection of pancreatic cancer. EBioMedicine. 2019; 41: 345-356.

42. Zvereva M, Roberti G, Durand G, Voegele C, Nguyen MD, Delhomme TM, et al. Circulating tumour-derived KRAS mutations in pancreatic cancer cases are predominantly carried by very short fragments of cell-free DNA. EBioMedicine 2020; 55: 102462.

43. Seet AO, Choo SP, Tai DW, Lam IY, Jing T, Tan Y, et al. Prognostic and predictive value4 of circulating tumour DNA (ctDNA) by amplicon-based next generation sequencing (NGS) of advanced pancreatic cancer (APC) in a phase I trial of oxoliplatin, capecitabine and irinotecan (OXIRI) triplet chemotherapy. J Clin Oncol. 2020; 38: 730.

44. Testa U, Pelosi E, Castelli G. Colorectal cancer: Genetic abnormalities, tumor progression, tumor heterogeneity, clonal evolution and tumor-initiating cells. Med Sci. 2018; 6:31.

45. The Cancer Atlas Genome Network. Comprehensive molecular characterization of human colon and rectal cancer. Nature. 2012; 487: 330-337.

46. Reinert T, Scholer LV, Thomsen R, Tobiasen H, Vang S, Nordentoft I, et al. Analysis of circulating tumor DNA to monitor disease burden following colorectal cancer surgery. Gut. 2016; 65: 625634.

47. Scholer LV, Reinert T, Ornoft MB, Kassentoft CG, Arnadottir SS, Vang S, et al. Clinical implications of monitoring circulating tumor DNA in patients with colorectal cancer. Clin Cancer Res. 2017; 23: 5437-5445.

48. Tie J, Wang Y, Tommasetti C, Li L, Springer S, Kinde I, et al. Circulating tumor DNA analysis detects minimal residual disease and predicts recurrence in patients with stage II colon cancer. Sci Trans Med. 2016; 8: 346ra92.

49. Wan N, Weinberg D, Liu TY, Niehaus K, Ariazi EA, Delubac D, et al. Machine learning enables detection of early-stage colorectal cancer by whole-genome sequencing of plasma cell-free DNA. BMC Cancer. 2019; 19: 832.

50. Phallen J, Sausen M, Adleff V, Leal A, Hruban C, White J, et al. Direct detection of early-stage cancers using circulating tumor DNA. Sci Transl Med. 2017; 9: eaan2415.

51. Yang YC, Wang D, Jin L, Yao HW, Zhang JH, Wang J, et al. Circulating tumor DNA detectable in early- and late-stage colorectal patients. Boiscience Rep. 2018; 38: BSR20180322.

52. Wang Y, Li L, Cohen JD, Kinde I, Ptak J, Popoli M, et al. Prognostic potential of circulating tumor DNA measurement in postoperative surveillance of nonmetastatic colorectal cancer. JAMA Oncol. 2019; 5: 1118-1123.

53. Reinert T, Henriksen TV, Christensen E, Sharma S, Salari R, Sethi H, et al. Analysis of plasma cellfree DNA by ultradeep sequencing in patients with stages I to III colorectal cancer. JAMA Oncol. 2019; 5: 1124-1131.

54. Tie J, Kinde I, Wang Y, Wong HL, Roebert J, Christie M, et al. Circulating tumor DNA as an early marker of therapeutic response in patients with metastatic colorectal cancer. Ann Oncol. 2015; 26: 1715-1722. 
55. Tie J, Cohen JD, Wang Y, Li L, Christie M, Simons K, et al. Serial circulating tumor DNA analysis during multimodality treatment of locally advanced rectal cancer: A prospective biomarker study. Gut. 2019; 68: 663-671.

56. Tie J, Cohen JD, Wang Y, Christie M, Simons K, Lee M, et al. Circulating tumor DNA analyses as markers of recurrence risk and benefit of adjuvant therapy for stage III colon cancer. JAMA oncol. 2019; 5: 1710-1717.

57. Tarazona N, Gimeno-Valiente F, Gambardella V, Zuniga S, Rentero-Garrido P, Huerta M, et al. Targeted next-generation sequencing of circulating-tumor DNA for tracking minimal residual disease in localized colon cancer. Ann Oncol. 2019; 30: 1804-1812.

58. Berger AW, Schwerdel D, Welz H, Marienfeld R, Schmidt SA, Kleger A, et al. Treatment monitoring in metastatic colorectal cancer patients by quantification and KRAS genotyping of circulating cell-free DNA. PLoS One. 2017; 12: e0174308.

59. Pairawan S, Hess KR, Janku F, Sanchez NS, Shaw KR, Eng C, et al. Cell-free circulating tumor DNA variant allele frequency associates with survival in metastatic cancer. Clin Cancer Res. 2020; 26: 1924-1931.

60. Osumi H, Shinozaki E, Yamaguchi K, Zembutsu H. Early change in circulating tumor DNA as a potential predictor of response to chemotherapy in patients with metastatic colorectal cancer. Scient Rep. 2019; 9: 17358.

61. Lyskjær I, Kronborg CS, Rasmussen MH, Sørensen BS, Demuth C, Rosenkilde M, et al. Correlation between early dynamics in circulating tumour DNA and outcome from FOLFIRI treatment in metastatic colorectal cancer. Scient Rep. 2019; 9: 11542.

62. Salem ME, Puccini A, Tie J. Redefining colon cancer by tumor biology. ASCO Educ Book. 2020; 40: 147-159.

63. Kang JK, Heo S, Kim HP, Song SH, Yun H, Han SW, et al. Liquid biopsy-based tumor profiling for metastatic colorectal cancer patients with ultra-deep targeted sequencing. PLoS One. 2020; 15: e0232754.

64. Furuki H, Yamada T, Takahashi G, Iwai T, Koizumi M, Shinji S, et al. Evaluation of liquid biopsies for detection of emerging mutated genes in metastatic colorectal cancer. Eur J Surg Oncol. 2018; 44: 975-982.

65. Elez E, Chianese C, Sanz-Garcia E, Martinelli E, Noguerido A, Manuco FM, et al. Impact of circulating tumor DNA mutant allele fraction on prognosis in RAS-mutant metastatic colorectal cancer. Mol Oncol. 2019; 13: 1827-1835.

66. Thierry AR, Mouliere F, El Messaoudi S, Mollevi C, Lopez-Crapez E, Rolet F, et al. Clinical validation of the detection of KRAs and BRAF mutations from circulating tum or DNA. Nat Med. 2014; 20: 430-435.

67. Bachet JB, Bouché O, Taieb J, Dubreuil O, Garcia ML, Meurisse A, et al. Ras mutation analysis in circulating tumor DNA from patients with metastatic colorectal cancer: AGEO RASANC prospective multicenter study. Ann Oncol. 2018; 29: 1211-1219.

68. Schmiegel W, Scott RJ, Dooley S, Lewis W, Meldrum CJ, Pockney P, et al. Blodd-based detection of RAS mutations to guide anti-EGFR therapy in colorectal cancer patients: Concordance of results from circulating tumor DNA and tissue-based RAS testing. Mol Oncol. 2017; 11: 208-219.

69. Vidal J, Muinelo L, Dalmases A, Jones F, Edelstein D, Iglesias M, et al. Plasma ctDNA RAS mutation analysis for the diagnosis and treatment monitoring of metastatic colorectal cancer patients. Ann Oncol. 2017; 28: 1325-1332. 
70. Grasselli J, Elez E, Caratù G, Matito J, Santos C, Macarulla T, et al. Concordance of blood- and tumor-based detection of RAS mutations to guide anti-EGFR therapy in metastatic colorectal cancer. Ann Oncol. 2017; 28: 1294-1301.

71. García-Foncillas J, Tabernero J, Élez E, Aranda E, Benavides M, Camps C, et al. Prospective multicenter real-world RAS mutation comparison between OncoBEAM-based liquid biopsy and tissue analysis in metastatic colorectal cancer. Br J Cancer. 2018; 119: 1464-1470.

72. Normanno N, Esposito Abate R, Lambiase M, Forgione L, Cardone C, lannaccone A, et al. RAS testing of liquid biopsy correlates with the outcome of metastatic colorectal cancer patients treated with first-line FOLFIRI plus cetuximab in the CAPRI-GOIM trial. Ann Oncol. 2018; 29: 112-118.

73. Thierry AR, El Messaoudi S, Mollevi C, Raoul JL, Guimbaud R, Pezet D, et al. Clinical utility of circulating DNA analysis for rapid detection of actionable mutations to select metastatic colorectal patients for anti-EGFR treatment. Ann Oncol. 2017; 28: 2149-2159.

74. Thierry AR, Pastor B, Jiang ZQ, Katsiampuora AD, Perseghian C, Loree JM, et al. Circulating DNA demonstrates convergent evolution and common resistance mechanisms during treatment of colorectal cancer. Clin Cancer Res. 2017; 23: 4578-4591.

75. Siena S, Sartore-Bianchi A, Garcia-Carbonero R, Karthaus M, Smith D, Tabernero J, et al. Dynamic molecular analysis and clinical correlates of tumor evolution within a phase II trial of panitumumab-based therapy in metastatic colorectal cancer. Ann Oncol. 2018; 29: 119-126.

76. Parseghian CM, Napolitano S, Loree JM, Kopetz S. Mechanism of innate and acquired resistance to anti-EGFR therapy: A review of current knowledge with a focus on rechallenge therapies. Clin Cancer Res. 2019; 25: 6899-6908.

77. Van Emburgh BO, Arena S, Siravegna G, Lazzari L, Crisafulli G, Corti G, et al. Acquire RAS or EGFR mutations and duration of response to EGFR blockade in colorectal cancer. Nat Commun. 2016; 7; 13665.

78. Shitara K, Yamazaki K, Uetake H, Kato T, Oki E, Yamanaka T, et al. Randomized phase Il study of regorafenib followed by cetuximab versus the reverse sequence for previously treated metastatic colorectal cancer patients (REVERCE). J Clin Oncol. 2014; 32: TPS3662.

79. Siravegna G, Mussolin B, Buscarino M, Corti G, Cassingena A, Crisafulli G, et al. Clonal evolution and resistance to EGFR blockade in the blood of colorectal cancer patients. Nat Med. 2015; 21: 795-801.

80. Parseghian CM, Loree JM, Morris VK, Liu X, Clifton KK, Napolitano S, et al. Anti-EGFR-resistant clones decay exponentially after progression: Implications for anti-EGFR re-challenge. Ann Oncol. 2019; 30: 243-249.

81. Cremolini C, Rossini D, Dell'Aquila E, Lonardi S, Conca E, Del Re M, et al. Rechallenge for patients with RAS and BRAF wild-type metastatic colorectal cancer with acquired resistance to first-line cetuximab and irinotecan: A phase 2 single-arm clinical trial. JAMA Oncol. 2019; 5: 343-350.

82. Siena S, Bardelli A, Sartore-Bianchi A, Lonardi S, Leone F, Leone F, et al. Abstract A089: Exploiting clonal evolution and liquid biopsy to overcome resistance to anti-EGFR treatment in metastatic colorectal cancer: The Chronos trial. Mol Cancer Ther. 2018; 17: A089.

83. Schirripa M, Biason P, Lonardi S, Pella N, Pino MS, Urbano F, et al. Class 1, 2 and 3 BRAF-mutated metastatic colorectal cancer: A detailed clinical, pathologic, and molecular characterization. Clin Cancer Res. 2019; 25: 3954-3963.

84. Van Helden EJ, Angus L, Menke - van der Houven van Oordt CW, Heideman DA, Boon E, Van Es $\mathrm{SC}$, et al. RAS and BRAF mutations in cell-free DNA are predictive for outcome of cetuximab 
monotherapy in patients with tissue-tested RAS wild-type advanced colorectal cancer. Mol Oncol 2019; 13: 2361-2374.

85. De Cuyper A, Van Den Eynde M, Machiuels JP. HER2 as a predictive biomarker and treatment target in colorectal cancer. Clin Colorectal Cancer. 2020; 19: 65-72.

86. Sawada K, Nakamura Y, Yamanaka T, Kuboki Y, Yamaguchi D, Yuki S, et al. Prognostic and predictive value of HER2 amplification in patients with metastatic colorectal cancer. Clin Colorectal Cancer. 2018; 17: 198-205.

87. Bregni G, Sciallero S, Sobrero A. HER2 amplification and anti-EGFR sensitivity in advancer colorectal cancer. JAMA Oncol. 2019; 5: 605-606.

88. Sartore-Bianchi A, Trusolino L, Martino C, Bencardino K, Lonardi S, Bergamo F, et al. Dualtargeted therapy with trastuzumab and lapatinib in treatment-refractory, KRAS codon 12/13 wild-type, HER2-positive metastatic colorectal cancer (HERACLES): A proof-of-concept, multicentre, open-label, phase 2 trial. Lancet Oncol. 2016; 17: 738-746.

89. Hainsworth JD, Meric-Bernstam F, Swanton C, Hurwitz H, Spigel DR, Sweeney C, et al. Targeted therapy for advanced solid tumors on the basis of molecular profiles: Results from Mypathy, an open-label, phase Ila multiple basket study. J Clin Oncol. 2018; 36: 536-542.

90. Siravegna G, Sartore-Bianchi A, Nagy RJ, Raghav K, Odegaard JI, Lanman RB, et al. Plasma HER2 (ERBB2) copy number predicts response to HER2-targeted therapy in metastatic colorectal cancer. Clin Cancer Res. 2019; 25: 3046-3053.

91. NaKamura Y, Sawada K, Fuji S, Yoshino T. HER2-targeted therapy should be shifted towards an earlier line for patients with ani-EGFR therapy naïve, HER2-amplified metastatic colorectal cancer. ESMO Open. 2019; 4: e000530.

92. Meric-Bernstam F, Hurwitz H, Raghav KP, McWilliams RR, Fakih M, VanderWalde A, et al. Pertuzumab plus trastuzumab for HER2-amplified metastatic colorectal cancer (MyPathway): An updated report from a multicentre, open-label, phase $2 a$, multiple basket study. Lancet Oncol. 2019; 20: 518-530.

93. Nakamura Y, Okamoto W, Kato T, Hasegawa H, Kato K, Iwasa S, et al. Triumph: Primary efficacy of a phase II trial of trastuzumab (T) and pertuzumab (P) in patients (PTS) with metastatic colorectal cancer (mCRC) with HER2 (ErbB2) amplification (AMP) in tumor tissue of circulating tumour DNA (ctDNA): A GOZILA sub-study. Annal of Oncol. 2019; 30: v198-v252.

94. Dong Z, Kong L, Wan Z, Zhu F, Zhong M, Lv Y, et al. Somatic mutation profiling and HER2 status in KRAS-positive chines colorectal cancer patients. Sci Rep. 2019; 9: 16894.

95. Sandhu J, Wang C, Fakih M. Clinical response to T-DM1 in HER2-amplified, KRAS-mutated mestatic colorectal cancer. J Natl Compr Cancer Netw. 2020; 18: 116-119.

96. Scimia M, Du J, Pepe F, Bianco MA, Spena SR, Patell-Socha F, et al. Evaluation of a novel liquid biopsy-based ColoScape assay for mutational analysis of colorectal neoplasia and triage of FIT+ patients: A pilot study. J Clin Pathol. 2018; 71: 1123-1126.

97. Rothwell DG, Ayub M, Cook N, Thistlethwaite F, Carter L, Dean E, et al. Utility of ctDNA to support patient selection for early phase clinical trials: The TARGET study. Nat Med. 2019; 25: 738-743.

98. Testa U, Castelli G, Pelosi E. Lung cancers: Molecular characterization, clonal heterogeneity and evolution, and cancer stem cells. Cancers. 2018; 10: 248.

99. Abbossh C, Birbak NJ, Wilson GA, Jamala-Hanjani M, Constantin T, Salari R, et al. Phylogenetic ctDNA analysis depicts early-stage lung cancer. Nature. 2017; 545: 446-451. 
100. Abbosh C, Frankell A, Garnett A, Harrison T, Weichert M, Licon A, et al. Phylogenetic tracking and minimal residual disease detection using ctDNA in early-stage NSCLC: A lung TRACERx study. Philadelphia, PA: American Association for Cancer Research; 2020; СT023.

101.Jiang J, Adams HP, Yao L, Yaung S, Lal P, Balasubramannyam A, et al. Concordance of genomic alterations by next-generation sequencing in tumour tissue versus cell-free DNA in stage I-IV non-small cell lung cancer. J Mol Diagn. 2020; 22: 228-235.

102.Soria JC, Ohe Y, Vensteenkiste J, Reungwtwattana T, Chewaskulyong B, Lee KH, et al. Osimertinib in untreated EGFR-mutated advanced non-small-cell lung cancer. N Engl J Med. 2018; 378: 113-125.

103.Wu YL, Zhou C, Liam CK, Wu G, Liu X, Zhong Z, et al. First-line erlotinib versus gemcitabine/cisplatin in patients with advanced EGFR mutation-positive non-small-cell lung cancer: Analyses from the phase III, randomized, open-label, ENSURE study. Ann Oncol. 2015; 26: 1883-1889.

104. Park CK, Cho HJ, Choi YD, Oh IJ, Kim YC. A phase II trial of Osimertinib in the second-line treatment of non-small cell lung cancer with the EGFR T790M mutation, detected from circulating tumor DNA: Liquid Lung-O-Cohort 2. Cancer Res Treat. 2019; 51: 777-787.

105. Gray JE, Okamoto I, Sriuranpong V, Vansteenkiste J, Imamura F, Lee JS, et al. Tissue and plasma mutation analysis in the FLAURA trial: Osimertinib vs comparator EGFR tyrosine kinase inhibitor as first-line treatment in patients with EGFR mutated advanced non-small cell lung cancer. Cancer Res. 2019; 25: 6644-6652.

106. Ishii H, Azuma K, Sakai K, Naito Y, Matsuo N, Tokito T, et al. Determination of somatic mutations and tumor mutation burden in plasma by CAPP-Seq during afatinib treatment in NSCLC patients resistance to Osimertinib. Sci Rep. 2020; 10: 691.

107. Bennouna J, Girard N, Audigier-Valette C, le Thuant A, Gervais R. Masson P, et al. Phase II study evaluating the mechanisms of resistance on tumor tissue and liquid biopsy in patients with EGFR-mutated non-pretreated advanced lung cancer receiving Osimertinib until and beyond radiologic progression: The MELROSE trial. Clin Lung Cancer. 2020; 21: e10-e14.

108. Oliveira KC, Ramos IB, Silva JM, Barra WF, Riggins GJ, Palande V, et al. Current perspectives on circulating tumor DNA, precision medicine, and personalized clinical management of cancer. Mol Cancer Res. 2020; 18: 517-528.

109. Leighl NB, Page RD, Raymond VM, Daniel DB, Divers SG, Reckamp KL, et al. Clnical utility of comprehensive cell-free DNA analysis to identify genomic biomarkers in patients with newly diagnosed metastatic non-small lung cancer. Clin Cancer Res. 2019; 25: 4691-4700.

110.Gandara DR, Paul SM, Kowanetz M, Schleifman E, Zou W, Li Y, et al. Blood-based tumor mutational burden as a predictor of clinical benefit in non-small-cell lung cancer patients treated with atezolizumab. Nat Med. 2018; 24: 1441-1448.

111. Wang Z, Duan J, Cai S, Han M, Dong H, Zhao J, et al. Assessment of blood tumor mutational burden as a potential biomarker for immunotherapy in patients with non-small cell lung cancer with use of a next-generation sequencing cancer gene panel. JAMA Oncol. 2019; 5: 606-702.

112. Anagnostou V, Forde PM, White JR, Niknafs N, Hruban C, Naidoo J, et al. Dynamics of tumor and immune responses during immune checkpoint blockade in non-small cell lung cancer. Cancer Res. 2019; 79: 1214-1225.

113. Li L, Wang Y, Shi W, Zhu M, Liu Z, Luo N, et al. Serial ultra-deep sequencing of circulating tumor DNA reveals the clonal evolution in non-small cell lung cancer patients treated with anti-PD1 immunotherapy. Cancer Med. 2019; 8: 7669-7678. 
114. Hellmann MD, Nabet BY, Rivzi H, Chaudhuri AA, Wells DK, Dunphy MP, et al. Circulating tumor DNA analysis to assess risk of progression after long-term response to PD-L1 blockade in NSCLC. Clin Cancer Res. 2020.

115. Mack PC, Banks KC, Espenchied CR, Burich RA, Zill OA, Lee CE, et al. Spectrum of driver mutations and clinical impact of circulating tumor DNA analysis in non-small cell lung cancer: Analysis of over 800 cases. Cancer. 2020; 126: 3219-3228.

116. Chabon JJ, Hamilton EQ, Kurtz DM, Esfahani MS, Moding EJ, Stehr H, et al. Integrative genomic features for non-invasive early lung cancer detection. Nature. 2020; 580: 245-251.

117. Testa U, Castelli G, Pelosi E. Melanoma: Genetic abnormalities, tumor progression, clonal evolution and tumor initiating cells. Med Sci. 2017; 5: 28.

118. Akbani R, Akdemir KC, Aksoy BA, Albert M, Ally A, Amin SB, et al. Genomic classification of cutaneous melanoma. Cell. 2015; 161: 1681-1696.

119. Váraljai R, Wistuba-Hamprecht K, Seremet T, Diaz JM, Nsengimana J, Sucker A, et al. Application of circulating cell-free tumor DNA profiles for therapeutic monitoring and outcome prediction in genetically heterogeneous metastatic melanoma. JCO Precis Oncol. 2019; 3: 1-10. doi:10.1200/PO.18.00229.

120. Knuever J, Weiss J, Persa OD, Kreuzer K, Mauch K, Hallek M, et al. The use of circulating cellfree tumor DNA in routine diagnostics of metastatic melanoma patients. Scient Rep. 2020; 10: 4940.

121. Braune J, Keller L, Schiller F, Graf E, Rafei-Shamsabadi D, Wehrle J, et al. Circulating tumor DNA allows early treatment monitoring in BRAF- and NRAS- mutant malignant melanoma. JCO Precis Oncol. 2020; 4: 20-31. doi:10.1200/PO.19.00174.

122. Lee JH, Saw RP, Thompson JF, Lo S, Spillane AJ, Shannon KF, et al. Pre-operative ctDNA predicts survival in high-risk stage III cutaneous melanoma patients. Ann Oncol. 2019; 30: 818-822.

123. Lee JH, Menzies AM, Carlino MS, McEvoy AC, Sandhu S, Weppler AM, et al. Longitudinal monitoring of ctDNA in patients with melanoma and brain metastases treated with immune checkpoint inhibitors. Clin Cancer Res. 2020.

124. Testa U, Castelli G, Pelosi E. Breast cancer: A molecularly heterogeneous disease needing subtype-specific treatments. Med Sci. 2020; 8: 18.

125. Razavi P, Chang MT, Xu G, Bandiamudi C, Ross DS, Vasan N, et al. The genomic landscape of endocrine-resistant advanced breast cancers. Cancer Cell. 2018; 34: 427-438.

126. Chandarlapaty S, Chen D, He W, Sung P, Samoila A, You D, et al. Prevalence of ESR1 mutations in cell-free DNA and outcomes in metastatic breast cancer: A secondary analysis of the BOLERO2 clinical trial. JAMA Oncol. 2016; 2: 1310-1315.

127. Lupini L, Moretti A, Bassi C, Schirone A, Pedriali M, Querzoli P, et al. High-sensitivity assay for monitoring ESR1 mutations in circulating cell-free DNA of breast cancer patients receiving endocrine therapy. Sci rep. 2018; 8: 4371.

128. André F, Ciruelos E, Rubovszky G, Campone M, Loibl S, Rugo S, et al. Alpelisib for PIK3CAmutated, hormone receptor-positive advanced breast cancer. N Engl J Med. 2019; 380: 19291940.

129. Moynahan ME, Chen D, He W, Sung P, Samoila A, You D, et al. Correlation between PIK3CA mutations in cell-free DNA and everolimus efficacy in HR+, HER2- advanced breast cancer: Results from BOLERO-2. Br J Cancer. 2017; 116: 726-730. 
130.Kodahl AR, Ehmen S, Palisgaard N, Jylling AM, Jensen JD, Lænkholm AV, et al. Correlation between circulating cell-free PIK3CA tumor DNA levels and treatment response in patients with PIK3CA-mutated metastatic breast cancer. Mol Oncol. 2018; 12: 925-935

131. O'Leary B, Hrebien S, Baerney M, Eribbens C, Garcia-Murillas, Jiang J, et al. Comparison of BEAMing and droplet digital PCR for circulating tumor DNA analysis. Clin Chem. 2019; 65: 14051413.

132. O'Leary B, Cutts RJ, Liu Y, Hrebien S, Huang X, Fenwick K, et al. The genetic landscape and clonal evolution of breast cancer resistance to Palbociclib plus fulvestrant in the PALOMA-3 trial. Cancer Discov. 2018; 8: 1390-1403.

133. O'Leary B, Hrebien S, Morden JP, Beaney M, Fribbens C, Huang X, et al. Erly circulating tumor DNA dynamics and clonal selection with Palbociclib and fulvestrant for breast cancer. Nat Commun. 2028; 9: 896.

134. Dawson SJ, Tsui D, Murtaza M, Biggs H, Rueda OM, Chin SF, et al. Analysis of circulating tumor DNA to monitor metastatic breast cancer. N Engl J Med. 2013; 368: 1199-1209.

135. Keup C, Benyaa K, Hauch S, Sprenger-Haussels M, Tewes M, Mach P, et al. Targeted deep sequencing revealed variants in cell-free DNA of hormone receptor-positive metastatic breast cancer patients. Cell Mol Life Sci. 2020; 77: 497-509.

136. Shibayama T, Low SK, Ono M, Kobayashi T, Kobayashi K, Fukada I, et al. Clinical significance of gene mutation in ctDNA analysis for hormone receptor-positive metastatic breast cancer. Breast Cancer Res Treat. 2020; 18: 331-341.

137. Cresswell GD, Nichol D, Spiteri I, Tari H, Zapata L, Heide T, et al. Mapping the breast cancer metastatic cascade onto ctDNA using genetic and epigenetic clonal tracking. Nat Commun. 2020; 11: 1446.

138. Hrebien S, Citi V, Garcia-Murillas I, Cutts R, Fenwick K, Kozarewa I, et al. Early ctDNA dynamics as a surrogate for progression-free survival in advancer breast cancer in BEECH trial. Ann Oncol. 2019; 30: 945-952.

139. Garcia-Murillas I, Chopra N, Comino-Mendez I, Beaney M, Tovet H, Cutts RJ, et al. Assessment of molecular relapse detection in early-stage breast cancer. JAMA Oncol. 2019; 5: 1473-1478.

140. McDonald BR, Contente-Cuomo T, Sammut SJ, Odenheimer-Bergman A, Ernst B, Perdigones N, et al. Personalized circulating tumor DNA analysis to detect residual disease neoadjuvant therapy in therapy cancer. Sci Transl Med. 2019; 11: eaax7392.

141. Magbanua MJ, Brown-Swigart L, Wu HT, Hirst GL, Yau C, Wolf DM, et al. Circulating tumor DNA in neoadjuvant treated breast cancer reflects response and survival. medRxiv. 2020.

142. Coombes RC, Page K, Salari R, Hastings RK, Armstrong A, Ahmed S, et al. Personalized detection of circulating tumor DNA antedates breast cancer metastatic recurrence. Clin Cancer Res. 2019; 25: 4255-4263.

143. Testa U, Castelli G, Pelosi E. Cellular and molecular mechanisms underlying prostate cancer development: Therapeutic implications. Medicines. 2019; 6: 82.

144.Schwarzenbach H, Alix-Panabieres C, Muller I, Letang N, Vendrell JP, Rebillard X, et al. Cell-free tumor DNA in blood plasma as a marker for circulating tumor cells in prostate cancer. Clin Cancer Res. 2009; 15: 1032-1038.

145. Chun F, Muller I, Lange I, Friederich MG, Erbersdobler A, Karakiewicz PI, et al. Circulating tumour-associated plasma DNA represents an independent and informative predictor of prostate cancer. BJU Int. 2006; 98: 544-548. 
146. Altimari A, D’Errico Grigioni A, Benedettini E, Gabusi E, Schiavina R, Martinelli A, et al. Diagnostic role of circulating free plasma DNA detection in patients with localized prostate cancer. Am J Clin Pathol. 2008; 129: 756-762.

147. Hennigan ST, Trostel SY, Terrigino NT, Voznesensky OS, Schaefer RJ, Whitlock NC, et al. Low abundance of circulating tumor DNA in localized prostate cancer. JCO Precis Oncol. 2019; 3: 113.

148. Wyatt AW, Ananla M, Aggarwal R, Beja K, Feng F, Youngren J, et al. Concordance of circulating tumor DNA and matched metastatic tissue biopsy in prostate cancer. J Natl Cancer Inst. 2017; 109.

149. Wyatt AW, Azad AA, Volik SV, Annala M, Beja K, McConeghy B, et al. Genomic alterations in cell-free DNA and enzalutamide resistance in castration-resistant prostate cancer. JAMA Oncol. 2016; 2: 1598-1606.

150. Azad AA, Volik SV, Wyatt AW, Haegert A, Le Bihan S, Bell RH, et al. Androgen receptor gene aberrations in circulating cell-free DNA: Biomarkers of therapeutic resistance in castrationresistant prostate cancer. Clin Cancer Res. 2015; 21: 2315-2324.

151. Conteduca V, Wetterskog D, Sharabiani MT, Grande E, Fernandez-Perez MP, Jayaram A, et al. Adrogen receptor gene status in plasma DNA associates with worse outcome on enzalutamide or abiraterone for castration-resistant prostate cancer: A multi-institution correlative biomarker study. Ann Oncol. 2017; 28: 1508-1516.

152. Annala M, Vandeherkhove G, Khalaf D, Taavitsainen S, Beja K, Warnen EW, et al. Circulating tumor DNA genomics correlate with resistance to abiraterone and enzalutamide in prostate cancer. Cancer Discov. 2018; 8: 444-457.

153. Choudhury AD, Werner L, Francini E, Wei XX, Ha G, Freeman SS, et al. Tumor fraction in cellfree DNA as a biomarker in prostate cancer. JCI Insight. 2018; 3: e122109.

154. Viswanathan SR, Ha G, Hoff AM, Wala JA, Carrot-Zhang J, Wghelan CW, et al. Structural alterations driving castration-resistant prostate cancer revealed by linked-read genome sequencing. Cell. 2018; 174: 433-447.

155. Goodall J, Mateo J, Yuan W, Mossop H, Porta N, Miranda S, et al. Circulating cell-free DNA to guide prostate cancer treatment with PARP inhibition. Cancer Discov. 2017; 7: 1006-1017.

156. Kohli M, Tan W, Zheng T, Wang A, Montesinos C, Wong C, et al. Clinical and genomic insights into circulation tumor DNA-based alterations across the spectrum of metastatic hormonesensitive and castrate-resistant prostate cancer. EBiomedicine. 2020; 54: 102728.

157. Beltran H, Romanel A, Conteduca V, Casiraghi N, Sigouros M, Franceschini GM, et al. Circulating tumor DNA profile recognizes transformation to castration-resistant neuroendocrine prostate cancer. J Clin Invest. 2020; 130: 1653-1668.

158. Razavi P, Li BT, Brown DN, Jung B, Hubell E, Shen R, et al. High-intensity sequencing reveals the sources of plasma circulating cell-free DNA variants. Nat Medicine. 2019; 25: 1928-1937.

159. Strickler JH, Loree JM, Ahronian LG, Parikh AR, Niedzwiecki D, Lima Pereira AA, et al. Genomic landscape of cell-free DNA in patients with colorectal cancer. Cancer Discov. 2018; 8: 164-173.

160. Parikh AR, Laehchiner I, Elagina L, Goyal L, Levovitz C, Siravegna G, et al. Liquid versus tissue biopsy for detecting acquired resistance and tumor heterogeneity in gastrointestinal cancers. Nat Medicine. 2019; 25: 1415-1421.

161. Azad TD, Chaudhuri AA, Fang P, Qiao Y, Easfahani MS, Chabon JJ, et al. Circulating tumor DNA analysis for detection of minimal residual disease after chemoradiotherapy for localized esophageal cancer. Gastroenterology. 2020; 158: 494-505. 
162. Lennon AM, Buchanan AH, Kinde I, Warren A, Honushefsky A, Cohain AT, et al. Feasibility of blood testing combined with PET-CT to screen for cancer and guide intervention. Science. 2020; 369: eabb9601.

163. Liu MC, Oxnard GR, Klein EA, Swanton C, Seiden MV, on behalf of CCGA Consortium. Sensitive and specific multi-cancer detection and localization using methylation signatures in cell-free DNA. Ann Oncol. 2020; 31: 745-759.

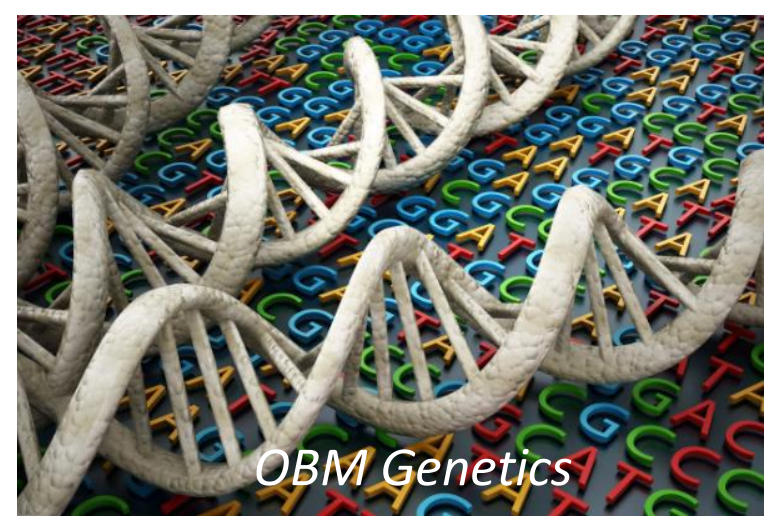

Enjoy OBM Genetics by:

1. Submitting a manuscript

2. Joining in volunteer reviewer bank

3. Joining Editorial Board

4. Guest editing a special issue

For more details, please visit:

http://www.lidsen.com/journals/genetics 